\title{
Competition through capacity investment under asymmetric existing capacities and costs
}

\author{
Shu-Jung Sunny Yang ${ }^{a *}$ Edward James Anderson ${ }^{b}$ \\ ${ }^{a}$ Essex Business School, University of Essex, sunnyy@essex.ac.uk \\ ${ }^{b}$ The University of Sydney Business School, edward.anderson@sydney.edu.au
}

05 February 2014

Forthcoming in European Journal of Operational Research

\begin{abstract}
This paper discusses the way that different operational characteristics including existing capacity, scale economies, and production policy have an important influence on the capacity outcomes when firms compete in the market place. We formulate a gametheoretical model where each firm has an existing capacity and faces both fixed and variable costs in purchasing additional capacity. Specifically, the firms simultaneously (or sequentially) make their expansion decisions, and then simultaneously decide their production decisions with these outputs being capacity constrained. We also compare our results with cases where production has to match capacity. By characterizing the firms' capacity and production choices in equilibrium, our analysis shows that the operational factors play a crucial role in determining what happens. The modeling and analysis in the paper gives insight into the way that the ability to use less production capacity than has been built will undermine the commitment value of existing capacity. If a commitment to full production is not possible, sinking operational costs can enable a firm to keep some preemptive advantage. We also show that the existence of fixed costs can introduce cases where there are either no pure strategy equilibrium or multiple equilibria. The managerial implications of our analysis are noted in the discussion. Our central contribution in this paper is the innovative integration of the strategic analysis of capacity expansion and well-known $(s, S)$ policy in operations and supply chain theory.
\end{abstract}

Keywords: capacity expansion; existing capacity; fixed cost; lead time; game theory; competitive strategy

\section{Introduction}

The objective of this paper is to increase our understanding of how the competitive asymmetries between existing capacities and between investment/production costs affect firm capacity decisions. When a firm faces a challenge from a competitor who can introduce new capacity (either an incumbent firm with existing capacity or a potential entrant), it can be hard to decide whether to respond aggressively to rivals through adding capacity (Hayes et al., 2005). The firm needs to make a tradeoff: making no response or making too small a capacity addition will result in accommodating the

\footnotetext{
*Corresponding Author.
} 
rival, while making too large a capacity addition will result in unused capacity or depressed prices. Furthermore, capacity decisions affect most, if not all, other operating decisions including production planning and inventory levels, human resource decisions, and decisions on logistics and distribution (Hendricks et al., 1995). So capacity response in a competitive environment is a crucial operations challenge with a significant impact on firm profitability. An important feature of this paper is that the combined impact of existing capacities and fixed costs of investment is considered in our formal analysis. Thus we can shed light on the means by which ex ante asymmetries in operational factors can influence the firm decision on responding to its rival's capacity expansion.

\subsection{Background}

There are two linked ideas that are important in understanding strategic capacity decisions. First, there is the notion that capacity can be accumulated. A firm may have some pre-existing capacity which is then added to by further investment. The second idea is that capacity acts as a constraint on production. Indeed, a firm's capacity is often defined as its maximum production rate. But research on competitive capacity investment has often dropped the second of these ideas: while maintaining the idea of accumulation, problems of analytic tractability have frequently led researchers to assume that a firm makes decisions on production and capacity at the same time (e.g., Anand and Girotra, 2007; Goyal and Netessine, 2007; Swinney et al., 2011). This leads to a clearance strategy in which a firm will use all of its capacity in production even if this turns out to be to its disadvantage. In our view this is only an appropriate model in cases where a firm has no option to make production decisions before discovering its rival's capacity choices (such as may occur if there are long lead times for major components); or, needs to maintain high capacity utilization because of high fixed costs of starting and stopping the production process; or, has available some mechanism to make a credible full production commitment to preempt the market (Hayes et al., 2005). Hence even though we use the terminology of a clearance strategy, as is normal in the operations management literature (see Van Mieghem and Dada, 1999), we do not mean to imply that a firm necessarily makes a choice about the strategy to use. It is more likely that a clearance strategy is a consequence of industry structure (Lieberman, 1987b; Goyal and Netessine, 2007).

In many circumstances firms first invest in capacity through building a factory or production line, and then operate the production facility over a period of months or years. When decisions on production quantities are made at a later time, it is often not possible to commit to a certain production level at the time when the capacity investment is made. In such cases firms may well choose to produce at a lower level than their maximum capacity (Hayes et al., 2005) and we refer to this as a holdback strategy following the operations management literature (see Van Mieghem and Dada, 1999). Note that we view the production policy, either holdback or clearance, as a fixed characteristic of the industry, but in practice the situation can be more complicated as firms need to make adjustments over time in response to market conditions. For instance in semiconductor manufacturing a firm may need to cut production when demand levels are falling, since if it sells all its capacity to the marketplace the resulting surplus production can push prices even lower (Wu et al., 2005). In this case the degree to which holdback is employed is a function of changing market 
conditions which are unknown at the outset. However, in this paper we concentrate on the simplest case in which a production quantity is set only once (following the operations literature including Anupindi and Jiang (2008)) and uncertainty in market conditions is sufficiently small that it can be ignored (following the economics literature including Dixit (1980)).

We will assume full information and in this case a firm can deduce its competitor's capacity investment decisions at the time that it makes its own investment. Thus no further information becomes available and there is nothing to stop a production decision being made at the time of investment (as occurs for example in Rhim et al. (2003)). But holdback production simply reflects the common circumstance that there is no mechanism for commitment to such a production decision in advance (Chen et al., 2002; Hayes et al., 2005). It is unclear in the literature whether, with holdback production, there might be a situation where in equilibrium a firm invests in capacity and this is not used. For example we might guess that when an aggressive large investment can ensure that a competitor will not invest, then this may lead to an equilibrium solution where the investing firm ends with more capacity than is needed. Our detailed analysis will show that this never happens in the holdback setting. Nevertheless using holdback will result in different equilibrium outcomes than the clearance case when only one of the firms invests.

The history of Du Pont fighting with Kerr-McGee in the U.S. bulk chemical industry (see Ghemawat, 1984) illustrates the fact that lead time is important in strategic capacity investment. In this case, the challenger in the industry, Kerr-McGee, announced its own capacity investment plan before the expansion of the incumbent, Du Pont, had fully materialized. The presence of significant lead time for adding capacity provided Kerr-McGee with the ability to force its competitor, Du Pont, to revise its initial capacity plan. This strategic response to a capacity expansion announcement meant that Du Pont was unable to increase its market share and allowed Kerr-McGee to avoid being in the strategically disadvantaged position of investment follower. This case shows that given the long lead time involved in capacity expansion, neither firm can move fast enough to establish a leader-follower environment. Koeva (2000) indicates that average lead time for significant capacity investments is 26 months for a range of 23 industries including utilities, chemical plants, and rubber processing plants. Thus, when there is a long lead time, capacity investment is best considered as a simultaneous move competition rather than a sequential move competition.

There is often a significant fixed cost that is incurred in capacity expansion in capital-intensive sectors for line production and process industries such as semiconductors, petrochemicals and flatpanel-monitor manufacturing, where production capacity is expensive and can take a long time to build (Hayes et al., 2005; Wu et al., 2005). In an empirical study of the U.S. petroleum refining industry, Asano (2002) shows that the size of fixed cost of investment is important to firms' investment decisions regardless of firm size. From the point of view of capacity strategy, we might expect that a fixed cost will raise a hurdle against small levels of investment and may make it easier for an incumbent to deter a new entrant by building excess capacity (e.g., Rhim et al., 2003).

In this paper, we will try to unravel the impact of a number of different operational factors mentioned above that can play a part in determining the outcomes of competitive capacity expansion. 


\subsection{Summary of Analysis}

We propose a game-theoretical model explicitly addressing the four factors we have mentioned: existing capacity, lead time, production policy, and investment fixed costs. Our work differs from the majority of papers in this area by explicitly considering the ex-ante asymmetries that exist in both existing capacities and investment costs.

By including a pre-existing capacity endowment for the two firms we are able to model both cases with an incumbent and an entrant. We will give a complete analysis including situations where one of the firms has a capacity endowment which is larger than would be optimal. This may happen when the game we analyze comes after some decisions on preliminary investment that are made with an uncertain forecast of the market size. Thus our model can be useful in analyzing the later stages of a more extended strategic competition with uncertainty at the first stage about final demand. Specifically, we are able to discuss a situation in which an incumbent firm has already taken the opportunity to build or buy additional capacity prior to an entering firm deciding on its capacity investment. In this environment an incumbent firm can still take the opportunity to build more capacity at the same time as the entering firm and our model is designed to reflect this.

We model a duopoly where each firm decides to invest $(I N V)$ or not to invest $(N I)$, and then chooses its capacity expansion level if it selects the $I N V$ strategy. The two firms produce the same or perfectly substitutable product; they both have access to the same deterministic forecast of demand; and, at the production stage, they know the capacity level of the other firm. Thus, after the capacity investment decisions have been made (the capacity game), the firms can evaluate their profit in a capacity-constrained production game. The market price is a function of the total production amount offered to the market by the two firms, and the production policy available to each firm (holdback or clearance) is fixed according to the industry structure.

We first characterize the pure-strategy Nash equilibrium in the production game and develop a best response function for each firm, given the capacity of its competitor, as a function of the initial capacities, the investment and operational costs, and the market structure parameters. Then, given plausible assumptions that the variable cost of capacity is not too high, we characterize the subgameperfect Nash equilibrium in the capacity game with simultaneous decisions. The equilibrium outcome in the alternating decision scheme is developed later for the sake of comparison. In the simultaneous decision setting, we show that all the various equilibrium possibilities can arise depending on the magnitude of existing capacity, even when other problem parameters are fixed. In this paper we will spend most time giving a thorough analysis of the problem with fixed costs, production holdback strategies, and simultaneous capacity decisions. This is the most difficult case to analyze and has been neglected in the literature up to now: arguably, this is the case that occurs most often in practice (see Hayes et al., 2005).

The lead time determines whether the appropriate model is one where the firms move simultaneously or where they move sequentially. Sequential capacity decisions can only occur when the lead time (i.e., the time required to make a firm commitment on capacity) is short enough so that one firm can act prior to its competitor making a capacity decision. In any other case it is better to model the game using simultaneous capacity decisions. 


\subsection{Related Literature}

The operations literature on competitive capacity expansion is not very extensive, since most attention has been focused on the monopoly setting: see Van Mieghem (2003) for a comprehensive survey. The majority of capacity expansion models with a single firm have given explicit consideration to fixed costs in order to demonstrate economies of scale in operations (e.g., Ye and Duenyas, 2007). However, most oligopoly models in this research stream ignore the existence of fixed costs in order to obtain analytical results (e.g., Anand and Girotra, 2007; Goyal and Netessine, 2007). For example, Van Mieghem and Dada (1999) consider several firms that produce the same product and face a linear demand curve with a stochastic intercept. Each of the firms has to decide on its capacity, production quantity, and price. They show that the price, capacity, inventory, and profit are increasing in demand variability. They consider firms that all employ holdback in production, but their results rely on firm symmetry to find a subgame perfect equilibrium in pure strategies for capacity competition. We complement this stream of research by incorporating fixed costs into a competitive capacity model without assuming that firms are symmetric (see, e.g., Chevalier-Roignant et al., 2011).

We will analyze duopoly models where two firms, with or without existing capacities, strategically invest in capacity in the presence of fixed costs and lead time. Similar models, frequently referred to as "commitment (entry) games" in the industrial organization (IO) literature, use deterministic demand and sunk/fixed costs in order to explain whether or not strategic excess capacity can be built either to deter new entry or to preempt existing rivals (e.g., Spulber, 1981). The entry-deterrence argument is that existing excess capacity enables incumbents to threaten to expand output and cut prices following entry, thereby making entry unprofitable. Hence, deterrence is achieved by intensifying the post-entry competition anticipated by the entrant. This strategic preemption increases the first mover's profit but lowers overall industry profit through this excess industry capacity (Dearden et al., 1999). Most IO models assume that firms use all of their available capacity (i.e., exercise clearance in production) even if the market-clearing price is below their variable costs. This assumption allows the interactions of firms' best response functions to be greatly simplified. However, Dixit (1980) and Ware (1984) point out that the pre-commitment is generally not perfect. While the investment decision is irrevocable, the capacity having been invested will be used only if it is profitable to do so (Krishnan and Röller, 1993). In other words, when competing firms can employ holdback in production then it becomes much harder to use a preemptive capacity expansion to deter an entrant. Our paper complements existing IO research by considering a simultaneous move game and allowing each firm to have some existing capacity; this allows a better match to situations that are prevalent in practice.

\section{Model Description}

There are two firms indexed $i=1,2$ in a duopoly: the firms are profit maximizers and risk neutral. This is a two-stage sequential game: specifically, investments are made in the first period (the capacity game) and production decisions are made in the second period (the production game). At the second stage a firm's output is subject to its capacity constraint: this is its initial capacity endowment plus any additional capacity arising from the investment in the first stage. We only consider the profits 
made from decisions on capacity investment in period 1 and production in period 2; so we ignore any production activity that takes place prior to period 2 using pre-existing capacity. Throughout this paper, we assume that all information is common knowledge.

In period 1, each firm can decide to either keep the same capacity level as the existing capacity amount $(N I)$, or increase capacity over the existing capacity amount $(I N V)$. At the start of the game, firm $i$ 's pre-existing capacity is $z_{i}$ and its capacity level after making the investment decision is denoted by $x_{i}$. Thus $x_{i} \geq z_{i} \geq 0$ and $x_{i}-z_{i}$ is the capacity addition for firm $i$. Capacity investment is costly and we suppose that there is a fixed cost of $K_{i}$ incurred in choosing the $I N V$ strategy. Investment is irreversible.

We assume that neither firm can delay its investment decision until it discovers the investment decision of the other; that is, any delay between the two firms' investment decision is sufficient small so that the first stage can be considered simultaneous. In period 2 , the firms simultaneously decide their production quantities (denoted by $y_{i} \geq 0$ ) given their investment decisions in period 1 . Note that production will usually take place over a long period; and thus the two periods are typically of very different lengths. Figure 1 summarizes the timing of our model. In Section 6 we will briefly discuss an alternating investment decision scheme, where the first stage is a sequential-move noncooperative game and the second stage remains as a simultaneous-move noncooperative game.

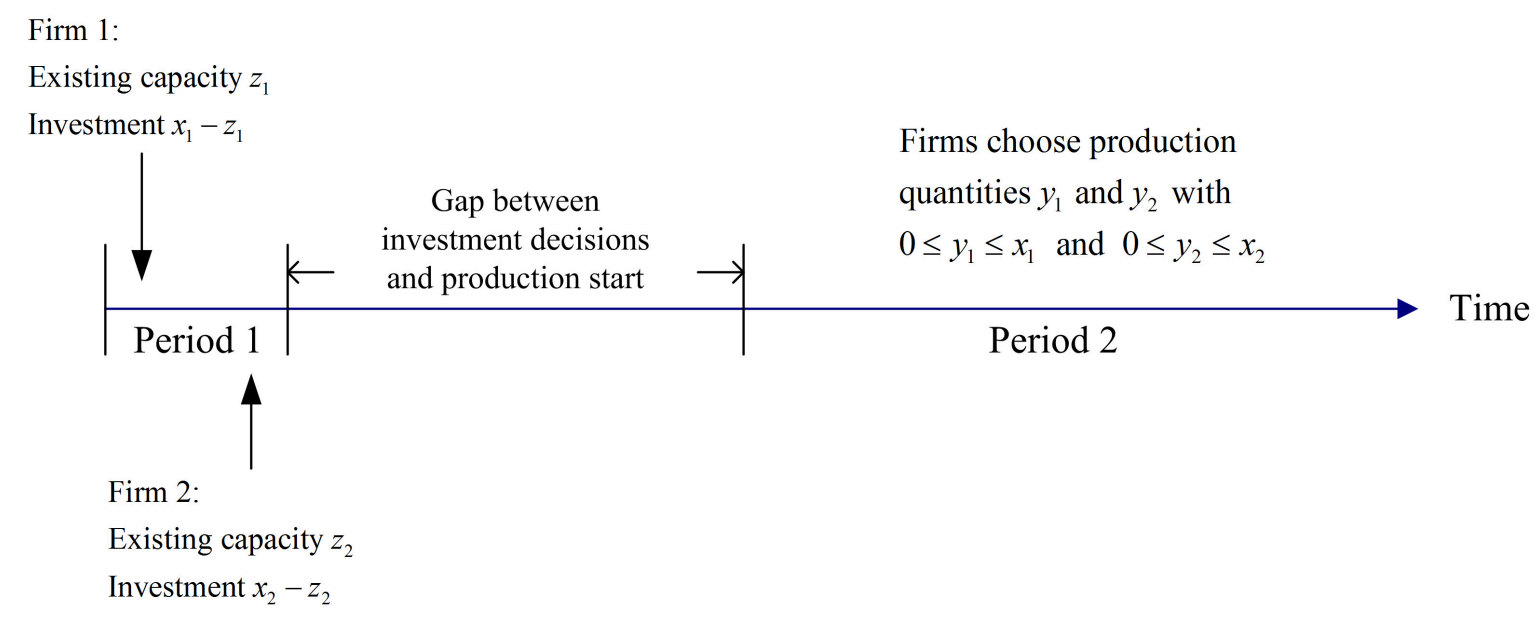

Figure 1: The Sequence of Events

A firm's total cost is made up of two parts. First, a capacity decision $x_{i}-z_{i}>0$ for firm $i$ incurs an investment cost $K_{i}+W_{i}\left(x_{i}-z_{i}\right)$, where $W_{i}$ is the cost per unit of investment (and there is zero cost if there is no investment and $x_{i}=z_{i}$ ). Second, the production decision $y_{i} \in\left[0, x_{i}\right]$ for firm $i$ involves an operational cost $V_{i} y_{i}$, where $V_{i}$ is the cost per unit of production.

The inverse demand curve is deterministic and linear, and we can always scale units such that the price is given by $P(Q)=A-Q$, where $Q \geq 0$ is the total supply put into the market by the two firms and the demand intercept $A$ is a positive constant. It has been argued that this model with firms competing in quantities (Cournot competition) is appropriate for the description of the medium to long-term equilibrium in a spot market (see Tirole, 1988). Within a capacity constrained environment even allowing Bertrand type price competition can lead to a Cournot competition at the point of 
capacity investment (Kreps and Scheinkman, 1983). In the same way Anupindi and Jiang (2008) have suggested that price competition can also be modeled in this way if firms have some flexibility to exercise control on quantity through production or delivery. Due to its analytical simplicity, the choice of linear demand is conventional and this is often a good approximation to more general demand functions (see Shapiro, 1986). A downward sloping linear inverse demand curve can also be thought of as the result of utility-maximizing behavior of customers with quadratic, additively separable utility functions (see Singh and Vives, 1984).

In the online supplementary material, we give the proofs that are not reported in the paper.

\section{Production Game with Holdback}

We begin with the production game. Suppose that firms have already played the first stage capacity game, and are endowed with capacities $x_{i}$ and $x_{j}$. In this second stage, the firms play a constrained quantity-setting game.

Upon observing the capacities $\left(x_{i}, x_{j}\right)$ and conjecturing firm $j$ 's output of $y_{j}$, firm $i$ solves the following decision problem:

$$
\pi_{i}\left(x_{i}, x_{j}\right)=\max _{y_{i} \in\left[0, x_{i}\right]}\left\{P\left(y_{i}+y_{j}\right) y_{i}-V_{i} y_{i}\right\},
$$

where the objective function is the operating profit of firm $i$ in period 2 and $P\left(y_{i}+y_{j}\right)=A-y_{i}-y_{j}$. Note that we do not include any discounting of the profits in this formulation, though a model with discounted cash flows can be converted into the form we give here with suitable changes in the parameters and units of quantity. The decision variable $y_{i}$ must lie in $\left[0, x_{i}\right]$ which is the feasible set of outputs given that firm $i$ employs holdback (if clearance is used then $y_{i}=x_{i}$ ). This yields the first-order optimality condition:

$$
\frac{\partial\left[P\left(y_{i}+y_{j}\right) y_{i}-V_{i} y_{i}\right]}{\partial y_{i}}=A-2 y_{i}-y_{j}-V_{i}=0
$$

and we can check that the second-order optimality conditions are satisfied. Solving for $y_{i}$ as a function of $y_{j}$ gives the best response of firm $i$ in production:

$$
y_{i}^{a}\left(y_{j}\right):=\frac{A-V_{i}-y_{j}}{2} .
$$

Without capacity constraints, the Nash equilibrium outcome in the production game can be calculated by solving the two best responses, $y_{i}^{a}(\cdot)$ and $y_{j}^{a}(\cdot)$, simultaneously. To do this, we need an assumption:

Assumption 1. $A-2 V_{i}+V_{j}>0$ for $i=1,2$ and $j \neq i$.

Then we have the following lemma:

Lemma 1. Under Assumption 1 and given infinite capacity for the two firms, the unique Nash equilibrium in the production game is $\left(y_{i}^{c}, y_{j}^{c}\right)$ where

$$
y_{i}^{c} \equiv \frac{A-2 V_{i}+V_{j}}{3} \quad \text { for } i=1,2 \text { and } j \neq i .
$$


Assumption 1 is needed in order to ensure that $y_{1}^{c}$ and $y_{2}^{c}$ are positive. Note that $\partial^{2} \pi_{i} / \partial y_{i}^{2}=$ $-2<0$ and $\partial \pi_{i} /\left(\partial y_{i} \partial y_{j}\right)=-1<0$ for $i=1,2$ and $j \neq i$, so the equilibrium output $\left(y_{i}^{c}, y_{j}^{c}\right)$ is unique. This assumption is commonly adopted in the analytical literature to ensure that the marginal cost of production and operations is lower than expected maximum price (i.e., $A$ ) and both firms have an incentive to sell positive quantities of their products in the market (see, e.g., Tirole, 1988). It also rules out the trivial case wherein it is never profitable to produce and sell products. In fact, many analytical operations management studies implicitly make this assumption by scaling production costs to zero (e.g., Anand and Girotra, 2007; Goyal and Netessine, 2007; Swinney et al., 2011).

If both firms' capacities exceed the equilibrium outputs (i.e., $x_{i} \geq y_{i}^{c}$ for $i=1,2$ ), the unique second-stage equilibrium in the production game is given by $\left(y_{1}^{c}, y_{2}^{c}\right)$. If $x_{i}<y_{i}^{c}$ and $x_{j}<y_{j}^{c}$, the unique equilibrium in the production game is given by $\left(x_{1}, x_{2}\right)$. This is because given that $y_{j}=x_{j}$, the best response of firm $i$ 's output, $y_{i}^{a}\left(x_{j}\right)$, is larger than firm $i$ 's capacity constraint of $x_{i}$, and a symmetric result holds for firm $j$. In the asymmetric case where $x_{i} \geq y_{i}^{c}$ but $x_{j}<y_{j}^{c}$, the equilibrium in production is described by the following result.

Lemma 2. When $x_{i} \geq y_{i}^{c}$ and $x_{j}<y_{j}^{c}$, where $i=1,2$ and $j \neq i$, the Nash equilibrium in the production game is $\left(\min \left[x_{i}, y_{i}^{a}\left(x_{j}\right)\right], x_{j}\right)$.

Proof. Given $y_{j}$, the operating profit function for firm $i, P\left(y_{i}+y_{j}\right) y_{i}-V_{i} y_{i}$, is quadratic with a maximum at $y_{i}^{a}\left(y_{j}\right)$. Hence, given a capacity constraint $y_{i} \leq x_{i}$ for firm $i$, the best response is $y_{i}=$ $\min \left[x_{i}, y_{i}^{a}\left(y_{j}\right)\right]$. So $y_{i}=\min \left[x_{i}, y_{i}^{a}\left(x_{j}\right)\right]$ is the best response to $y_{j}=x_{j}$. To show a Nash equilibrium, it only remains to prove that $y_{j}=x_{j}$ is the best response to $y_{i}=\min \left[x_{i}, y_{i}^{a}\left(x_{j}\right)\right]$. Due to the fact that $y_{i} \leq y_{i}^{a}\left(x_{j}\right)$ we know that $2 y_{i} \leq A-V_{i}-x_{j}$ and $x_{j}<y_{j}^{c}$ implies $3 x_{j}<A-2 V_{j}+V_{i}$. Adding these inequalities we have $2 y_{i}<2 A-2 V_{j}-4 x_{j}$. Rearranging this gives $x_{j}<y_{j}^{a}\left(y_{i}\right)$ which in turn establishes $y_{j}=x_{j}$ as required.

Figure 2 maps the first-stage capacity choices onto the second-stage equilibrium output choices, according to Lemmas 1 and 2. The combination of capacity levels gives rise to four possible outcomes of the production game. The four regions identified in the figure are defined as follows:

$$
\begin{aligned}
& \Phi_{0} \equiv\left\{\left(x_{i}, x_{j}\right) \mid 0 \leq x_{i}<y_{i}^{a}\left(x_{j}\right) \text { and } 0 \leq x_{j}<y_{j}^{a}\left(x_{i}\right)\right\} \\
& \Phi_{4} \equiv\left\{\left(x_{i}, x_{j}\right) \quad 0 \leq x_{i}<y_{i}^{c} \text { and } x_{j} \geq y_{j}^{a}\left(x_{i}\right)\right\}, \\
& \Phi_{5} \equiv\left\{\left(x_{i}, x_{j}\right) \quad x_{i} \geq y_{i}^{a}\left(x_{j}\right) \text { and } 0 \leq x_{j}<y_{j}^{c}\right\}, \\
& \Phi_{6} \equiv\left\{\left(x_{i}, x_{j}\right) \mid x_{i} \geq y_{i}^{c} \text { and } x_{j} \geq y_{j}^{c}\right\} \text {. }
\end{aligned}
$$

The numbering here arises because of the further sets $\Phi_{1}, \Phi_{2}$ and $\Phi_{3}$ used in the proof of Theorem 1 and defined in the online supplementary material. We can summarize our results for the production game under holdback production as follows.

Lemma 3. Suppose that Assumption 1 holds. The equilibrium behavior in the production holdback game is:

(i) if $\left(x_{i}, x_{j}\right) \in \Phi_{0}$, the equilibrium outputs are $x_{i}$ and $x_{j}$; 


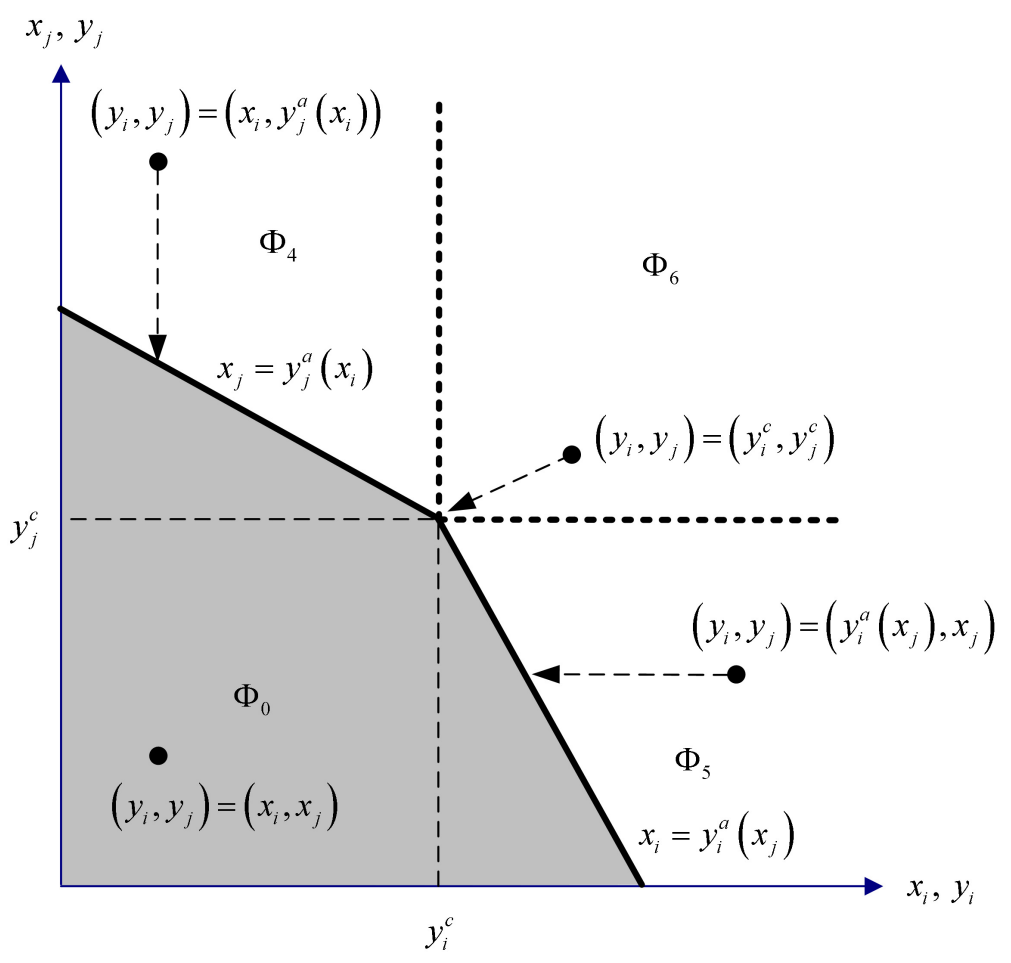

Figure 2: Mapping of Capacity onto Production Equilibrium

(ii) if $\left(x_{i}, x_{j}\right) \in \Phi_{4}$, the equilibrium outputs are $x_{i}$ and $y_{j}^{a}\left(x_{i}\right)$;

(iii) if $\left(x_{i}, x_{j}\right) \in \Phi_{5}$, the equilibrium outputs are $y_{i}^{a}\left(x_{j}\right)$ and $x_{j}$;

(iv) if $\left(x_{i}, x_{j}\right) \in \Phi_{6}$, the equilibrium outputs are $y_{i}^{c}$ and $y_{j}^{c}$.

This result is similar to Eaton and Ware (1987) and Krishnan and Röller (1993), but under different cost functions for investment and production activities.

\section{Best Response in Capacity Game}

Now we are ready to consider the choice of capacity investment at the first stage. In order to simplify the problem, we strengthen Assumption 1 to give:

Assumption 2. $A-2 V_{i}+V_{j}>6 W_{i} \quad$ for $i=1,2$ and $j \neq i$.

We can write this assumption as $y_{i}^{c}>2 W_{i}$ for $i=1,2$. This is an assumption that will be satisfied in most situations unless the market is very price inelastic and the variable cost of additional capacity is high. It is possible to derive best response functions without making this assumption, but it gives rise to a large number of cases and it is still necessary to make some other assumptions to derive an analytical solution to the capacity game. By introducing this assumption, we can avoid trivialities that capacity levels after the investment are less than the equilibrium outcomes in the production game. As for Assumption 1, this assumption and its variants have been implicitly imposed in many analytical capacity-related studies to ensure that capacity investment is still profitable even if both firms expand their capacity levels at the same time, see Section 5 for the details. 
Given firm $j$ 's capacity choice of $x_{j}$, firm $i$ 's operating profit function can be derived from Lemma 3 :

$$
\begin{aligned}
\pi_{i}\left(x_{i}, x_{j}\right) & =P\left(x_{i}+x_{j}\right) x_{i}-V_{i} x_{i} & & \text { if }\left(x_{i}, x_{j}\right) \in \Phi_{0}, \\
& =P\left(x_{i}+y_{j}^{a}\left(x_{i}\right)\right) x_{i}-V_{i} x_{i} & & \text { if }\left(x_{i}, x_{j}\right) \in \Phi_{4}, \\
& =P\left(y_{i}^{a}\left(x_{j}\right)+x_{j}\right) y_{i}^{a}\left(x_{j}\right)-V_{i} y_{i}^{a}\left(x_{j}\right) & & \text { if }\left(x_{i}, x_{j}\right) \in \Phi_{5}, \\
& =P\left(y_{i}^{c}+y_{j}^{c}\right) y_{i}^{c}-V_{i} y_{i}^{c} & & \text { if }\left(x_{i}, x_{j}\right) \in \Phi_{6} .
\end{aligned}
$$

Let

$$
R_{i}\left(x_{i}, x_{j}\right):=\pi_{i}\left(x_{i}, x_{j}\right)-W_{i}\left(x_{i}-z_{i}\right)-K_{i}
$$

be the profit of firm $i$, net of investment and production costs. Observing the existing capacity pair $\left(z_{i}, z_{j}\right)$ and conjecturing firm $j$ 's capacity choice of $x_{j}$, firm $i$ 's optimal profit at the investment stage is

$$
\Pi_{i}\left(z_{i}, x_{j}\right)= \begin{cases}\pi_{i}\left(z_{i}, x_{j}\right) & \text { if } \pi_{i}\left(z_{i}, x_{j}\right) \geq R_{i}\left(x_{i}^{*}, x_{j}\right), \\ R_{i}\left(x_{i}^{*}, x_{j}\right) & \text { otherwise, }\end{cases}
$$

where $x_{i}^{*}$ is the maximizer of function $R_{i}\left(x_{i}, x_{j}\right)$ subject to $x_{i}>z_{i}$ with the given $x_{j}$. The equation for $\Pi_{i}$ shows that given $z_{i}$ and $x_{j}$, firm $i$ invests up to $x_{i}^{*}$ if the return from this investment is over the investment expense; otherwise, the firm does not invest. From this observation, we can expect that the best response of firm $i$ 's investment to its rival's decision $x_{j}$ will depend on some threshold. If firm $i$ 's existing capacity $z_{i}$ is above the threshold, then its profit without investing is high enough and it should not build any new capacity; if not, it should build an additional amount of capacity $x_{i}^{*}-z_{i}$. However, we can be certain of this behavior only if the profit function $\pi_{i}\left(z_{i}, x_{j}\right)$ is monotonic in $z_{i}$ for the range $0 \leq z_{i} \leq x_{i}^{*}$ corresponding to $R_{i}\left(\cdot, x_{j}\right)$ being unimodal. In our case it turns out that the functions involved may not be unimodal. Nevertheless, using a careful analysis (given in the proof of the next result) we can show that it is still possible to characterize firm $i$ 's best response in the capacity game for a given capacity choice of firm $j$ and the existing capacity of firm $i$ using the same kind of approach. The result is given in Theorem 1 and a symmetric result holds for the best response of firm $j$.

Theorem 1. Let

$$
\begin{aligned}
S_{i}^{L}\left(x_{j}\right) & \equiv y_{i}^{a}\left(x_{j}\right)-\frac{W_{i}}{2} \\
s_{i}^{L}\left(x_{j}\right) & \equiv S_{i}^{L}\left(x_{j}\right)-\sqrt{K_{i}} \\
s_{i}^{B} & \equiv \frac{3}{2} y_{i}^{c}-W_{i}-\sqrt{2 K_{i}+\left(\frac{y_{i}^{c}}{2}-W_{i}\right)^{2}} \\
\vartheta_{i} & \equiv A-V_{i}-W_{i}-2 \sqrt{y_{i}^{c}\left(y_{i}^{c}-W_{i}\right)}, \text { and } \\
\phi_{i}\left(x_{j}\right) & \equiv S_{i}^{L}\left(x_{j}\right)-\sqrt{\left(S_{i}^{L}\left(x_{j}\right)\right)^{2}-y_{i}^{c}\left(y_{i}^{c}-W_{i}\right)+K_{i}} .
\end{aligned}
$$

If Assumption 2 holds and there is holdback in production, then an optimal response for firm $i$, given firm $j$ 's capacity decision $x_{j}$, is

$$
x_{i}^{*}\left(x_{j}\right)= \begin{cases}S_{i}\left(x_{j}\right) & \text { if } z_{i} \leq s_{i}\left(x_{j}\right), \\ z_{i} & \text { otherwise }\end{cases}
$$


where the expansion level function of firm $i$ is

$$
S_{i}\left(x_{j}\right) \equiv \begin{cases}S_{i}^{L}\left(x_{j}\right) & \text { for } x_{j} \leq \vartheta_{i} \\ y_{i}^{c} & \text { for } x_{j}>\vartheta_{i} .\end{cases}
$$

and the expansion point function of firm $i$ is

$$
s_{i}\left(x_{j}\right) \equiv \begin{cases}s_{i}^{L}\left(x_{j}\right) & \text { for } x_{j}<\vartheta_{i}, \\ \phi_{i}\left(x_{j}\right) & \text { for } \vartheta_{i} \leq x_{j}<y_{j}^{a}\left(s_{i}^{B}\right), \\ s_{i}^{B} & \text { for } x_{j} \geq y_{j}^{a}\left(s_{i}^{B}\right) .\end{cases}
$$

We refer to $s_{i}$ as the expansion point function and $S_{i}$ as the expansion level function. When the existing capacity $z_{i}$ is at the expansion point then the firm is indifferent between investing in additional capacity and not investing. The result of the above theorem is similar to the famous two-critical number $(s, S)$ policy from inventory theory (Scarf, 1960): Given the rival's available capacity, when the cumulative capacity is below the expansion point, it is optimal to bring it up to the expansion level; otherwise, it is optimal to leave it unchanged. Note that the expansion point and the expansion level depend on the other firm's capacity choice in the first stage. It is not hard to show that the function $s_{i}$ is continuous (for details see the online supplementary material) but the function $S_{i}$ is not continuous, as shown in Figure 3.

The intuition behind Theorem 1 is as follows. When firm $j$ 's capacity choice of $x_{j}$ is lower than $\vartheta_{i}$ and firm $i$ 's initial capacity of $z_{i}$ is less than the expansion point, i.e., $\left(z_{i}, x_{j}\right) \in \Omega_{1}\left(\Omega_{1}, \Omega_{2}\right.$, and $\Omega_{3}$ are defined in Figure 3), firm $i$ will invest up to $S_{i}^{L}\left(x_{j}\right)$ based on its profit maximization and both firms will produce up to their capacities in the production game. When $\left(z_{i}, x_{j}\right) \in \Omega_{2}$, firm $i$ should invest up to $y_{i}^{c}$. This has the effect of forcing firm $j$ to produce at a level $y_{j}^{c}$ which is less than its capacity $x_{j}$ (in the proof we show that in this region $\left.y_{j}^{c}<\vartheta_{i}<x_{j}\right)$. When $\left(z_{i}, x_{j}\right) \in \Omega_{3}$, firm $i$ will not invest since the production return from any investment activity is less than the investment expense.

As is clear from Figure 3, for certain values of existing capacity $z_{i}$, the best response of firm $i$ moves from investing to not investing and then back to investing as the capacity choice of firm $j$ increases. The calculation of the best response function is complex because of the holdback possibility in production. Even without the fixed costs $K_{i}$ we still obtain a curved boundary given by the function $\phi_{i}$.

\section{Equilibrium Analysis}

After analyzing the production game and the best responses in the capacity game, we now consider the firms' equilibrium behavior in the capacity game. It will be helpful to begin by defining some preliminary quantities. We define $\left(x_{i}^{C}, x_{j}^{C}\right)$ as the intersection point of functions $S_{i}^{L}(\cdot)$ and $S_{j}^{L}(\cdot)$, and thus the point we reach if both firms decide to invest. We have

$$
x_{i}^{C} \equiv y_{i}^{c}-\frac{2 W_{i}-W_{j}}{3} \text { for } i=1,2 \text { and } j \neq i .
$$

Assumption 2 makes $A-2 V_{i}+V_{j}-2 W_{i}+W_{j}>0$ and $A-2 V_{j}+V_{i}-2 W_{j}+W_{i}>0$, so the values of $x_{i}^{C}$ and $x_{j}^{C}$ are positive. Note that $S_{i}(\cdot)$ intersects $S_{j}(\cdot)$ only once at the point $\left(x_{i}^{C}, x_{j}^{C}\right)$ under the following mild assumption: 


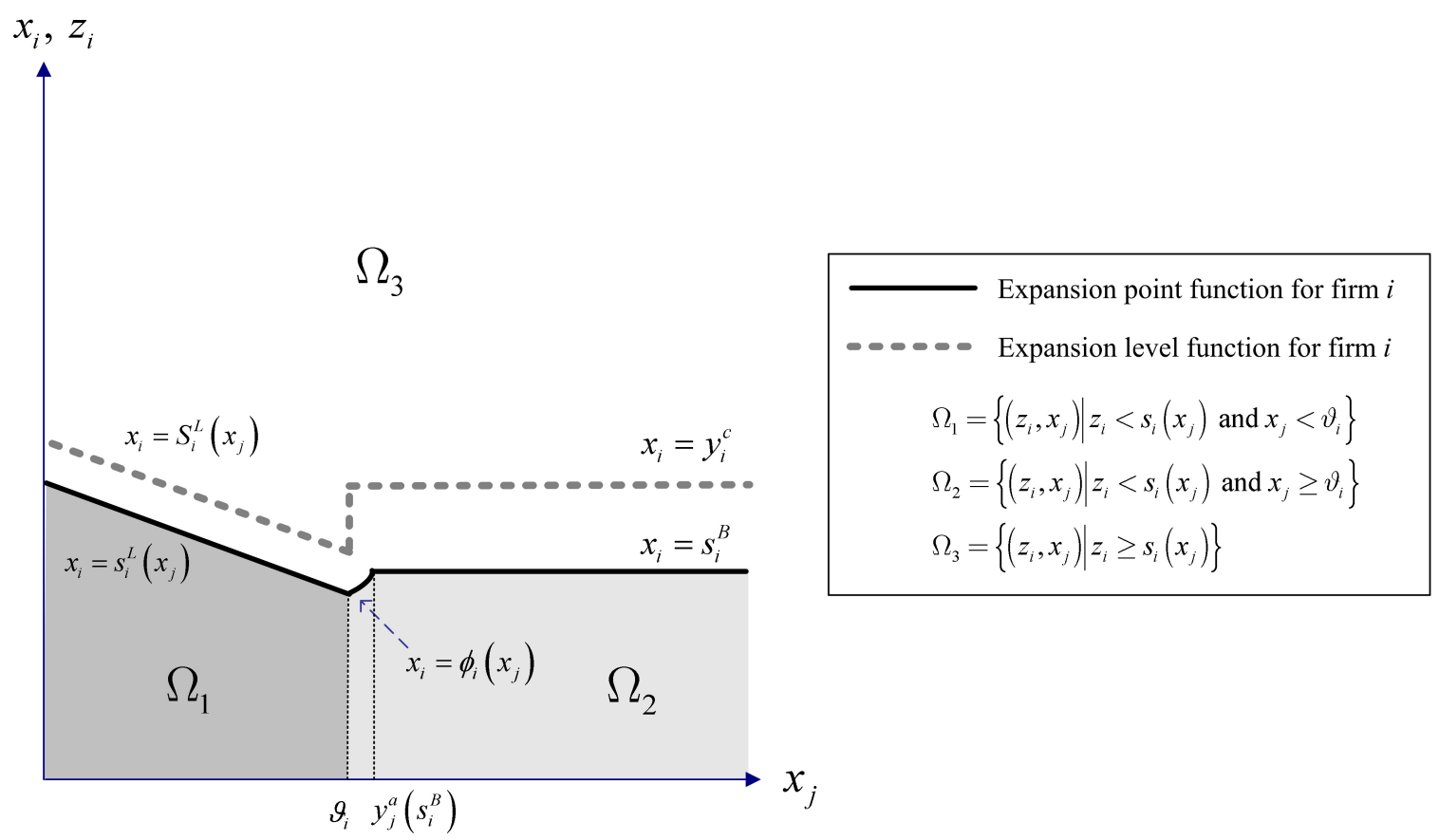

Figure 3: The Best Response of Firm $i$ in Capacity Game with Holdback Production

Assumption 3. $W_{i} \leq 2 W_{j}$ for $i=1,2$ and $j \neq i$.

Under this assumption, the uniqueness of the (INV, INV) strategy is assured. It is noted that this sort of assumption and its variants have been explicitly or implicitly adopted in most analytical literatures on capacity competition and industrial organization (see, e.g., Tirole, 1988).

We define

$$
b_{i} \equiv s_{i}\left(x_{j}^{C}\right) \text { and } b_{j} \equiv s_{j}\left(x_{i}^{C}\right) .
$$

Thus $b_{i}$ is the largest value of $z_{i}$ for which firm $i$ invests, given that firm $j$ also invests (so that we reach a solution where both firms invest).

Finally, we define $c_{i}$ as the solution of the equation

$$
c=s_{i}\left(S_{j}^{L}(c)\right) .
$$

We can describe this as the smallest value of $z_{i}$ for which firm $i$ does not invest, given that firm $j$ does invest, and firm $j$ chooses its investment amount assuming firm $i$ does not invest. Consideration of the geometry of the situation shows that there can only be one solution of (1). The slope of $S_{j}^{L}(\cdot)$ is -2 . We look for the intersection of this with the expansion point function $s_{i}^{-1}(\cdot)$, shown as a bold line in the left illustration of Figure 3. Since the slope of the $s_{i}^{-1}(\cdot)$ line below $\vartheta_{i}$ is $-1 / 2$, this line can only intersect $S_{j}^{L}(\cdot)$ from above. Note that this also implies that

$$
z<s_{i}\left(S_{j}^{L}(z)\right) \text { if and only if } z<c_{i} \text {. }
$$

Because the values of $b_{i}$ and $c_{i}$ depend on the form of $s_{i}(\cdot)$, it is not straightforward to write closed-form formulae for either of them. 
The best response function derived in the last section puts us in a position to determine the equilibrium of the capacity game. We limit our analysis to subgame-perfect Nash equilibrium in pure strategies (SPNE) that are described in the following theorem.

Theorem 2. Suppose that Assumptions 2 and 3 hold. Then,

(i) the $(I N V, I N V)$ strategy with $\left(x_{i}, x_{j}\right)=\left(x_{i}^{C}, x_{j}^{C}\right)$ is a SPNE in the capacity game if and only if the existing capacities satisfy condition $(A): z_{i}<b_{i}$ and $z_{j}<b_{j}$;

(ii) the (INV, NI) strategy with $\left(x_{i}, x_{j}\right)=\left(S_{i}^{L}\left(z_{j}\right), z_{j}\right)$ is a SPNE in the capacity game if and only if the existing capacities satisfy condition $(B): z_{i}<s_{i}\left(z_{j}\right)$ and $c_{j} \leq z_{j}<\vartheta_{i}$;

(iii) the (INV, NI) strategy with $\left(x_{i}, x_{j}\right)=\left(y_{i}^{c}, z_{j}\right)$ is a SPNE in the capacity game if and only if the existing capacities satisfy condition $(D): z_{i}<s_{i}\left(z_{j}\right)$ and $z_{j} \geq \vartheta_{i}$;

(iv) the (NI, NI) strategy with $\left(x_{i}, x_{j}\right)=\left(z_{i}, z_{j}\right)$ is a SPNE in the capacity game if and only if the existing capacities satisfy condition $(F): z_{i} \geq s_{i}\left(z_{j}\right)$ and $z_{j} \geq s_{j}\left(z_{i}\right)$.

\section{Proof.}

Part (i). Let $\left(x_{i}^{C}, x_{j}^{C}\right)$ be a SPNE for the capacity game. That is firm $i$ chooses to invest up to $x_{i}^{C}$ and hence, by Theorem $1, z_{i}<s_{i}\left(x_{j}^{C}\right)$; at the same time, firm $j$ chooses to invest up to $x_{j}^{C}$ and so, $z_{j}<s_{j}\left(x_{i}^{C}\right)$. This establishes the result in one direction. Conversely, under the conditions $z_{i}<s_{i}\left(x_{j}^{C}\right)$ and $z_{j}<s_{j}\left(x_{i}^{C}\right)$, if firm $j$ invests to the level $x_{j}^{C}$, then the firm $i$ will invest to the level $S_{i}^{L}\left(x_{j}^{C}\right)=x_{i}^{C}$ by Theorem 1 . And, similarly if firm $i$ invests to the level $x_{i}^{C}$. So $\left(x_{i}^{C}, x_{j}^{C}\right)$ is a SPNE for the capacity game.

Part (ii). Let $\left(S_{i}^{L}\left(z_{j}\right), z_{j}\right)$ be a SPNE for the capacity game. Thus firm $i$ chooses to invest up to $S_{i}^{L}\left(z_{j}\right)$ and hence, from Theorem $1, z_{i}<s_{i}\left(z_{j}\right)$ and $z_{j}<\vartheta_{i}$; at the same time, firm $j$ does not invest and so, $z_{j} \geq s_{j}\left(S_{i}^{L}\left(z_{j}\right)\right)$. Thus, from our previous observation (2) (Section 5), we have $z_{j} \geq c_{j}$. This establishes the result in one direction. Conversely, under conditions $z_{i}<s_{i}\left(z_{j}\right)$ and $c_{j} \leq z_{j}<\vartheta_{i}$, if firm $j$ chooses not to expand its capacity level, then the firm $i$ will invest to the level $S_{i}^{L}\left(z_{j}\right)$ by Theorem 1. Since we have $c_{j} \leq z_{j}<\vartheta_{i}$, we can conclude from (2) that $z_{j} \geq s_{j}\left(S_{i}^{L}\left(z_{j}\right)\right)$. Hence, if firm $i$ invests to the level $S_{i}^{L}\left(z_{j}\right)$, then the firm $j$ chooses not to expand its capacity level. So $\left(S_{i}^{L}\left(z_{j}\right), z_{j}\right)$ is a SPNE for the capacity game.

The other parts of the Theorem follow similarly.

Parts (ii) and (iii) of the above theorem have symmetric versions with the roles of $i$ and $j$ reversed, i.e., conditions $(\mathrm{C}): z_{j}<s_{j}\left(z_{i}\right)$ and $c_{i} \leq z_{i}<\vartheta_{j}$; and $(\mathrm{E}): z_{j}<s_{j}\left(z_{i}\right)$ and $z_{i} \geq \vartheta_{j}$.

Applying this theorem, we can find the corresponding SPNE for the ten possible regions $\Lambda_{1}, \ldots, \Lambda_{10}$ listed in Table 1 and shown in Figure 4. The example shown in Figure 4 is one which satisfies the following two conditions: First,

$$
b_{i}>c_{i} \text { for } i=1,2
$$


and second,

$$
x_{i}^{s}<\vartheta_{j} \quad \text { for } i=1,2 \text { and } j \neq i
$$

where $\left(x_{i}^{s}, x_{j}^{s}\right)$ is the intersection point of function $s_{i}(\cdot)$ and $s_{j}(\cdot)$. Under these two conditions, there are overlaps between the regions applying for parts (i) and (ii) of Theorem 2. In other words, these conditions imply that regions $\Lambda_{2}, \Lambda_{3}, \Lambda_{4}$, and $\Lambda_{9}$ will exist. Without condition (3), there may be no SPNE for some choices of parameters having

$$
b_{j} \leq z_{j}<s_{j}\left(S_{i}^{L}\left(z_{j}\right)\right)
$$

In Section 5.1, we will give numerical examples for which no SPNE exists for certain existing capacities, and for which either condition (3) or (4) does not hold. Notice that our results in Theorem 2 and Table 1 are general - without the restriction of conditions (3) and (4) - and only restricted by Assumptions 2 and 3.

Table 1: Equilibrium Behavior in Capacity Game

\begin{tabular}{cccc}
\hline Region & Conditions Satisfied & SPNE of Investment Strategy & Equilibrium Capacity \\
\hline$\Lambda_{1}$ & $(A)$ & $(I N V, I N V)$ & $\left(x_{i}^{C}, x_{j}^{C}\right)$ \\
$\Lambda_{2}$ & $(A),(B)$, and $(C)$ & $(I N V, I N V),(I N V, N I)$ & $\left(x_{i}^{C}, x_{j}^{C}\right),\left(y_{i}^{a}\left(z_{j}\right)-W_{i} / 2, z_{j}\right)$ \\
$\Lambda_{3}$ & $(A)$ and $(B)$ & $(I N V, I N V)$ and $(I N V, N I)$ & $\left(x_{i}^{C}, x_{j}^{C}\right)$ and $\left(y_{i}^{a}\left(z_{j}\right)-W_{i} / 2, z_{j}\right)$ \\
$\Lambda_{4}$ & $(A)$ and $(C)$ & $(I N V, I N V)$ and $(N I, I N V)$ & $\left(x_{i}^{C}, x_{j}^{C}\right)$ and $\left(z_{i}, y_{j}^{a}\left(z_{i}\right)-W_{j} / 2\right)$ \\
$\Lambda_{5}$ & $(B)$ & $(I N V, N I)$ & $\left(y_{i}^{a}\left(z_{j}\right)-W_{i} / 2, z_{j}\right)$ \\
$\Lambda_{6}$ & $(C)$ & $(N I, I N V)$ & $\left(z_{i}, y_{j}^{a}\left(z_{i}\right)-W_{j} / 2\right)$ \\
$\Lambda_{7}$ & $(D)$ & $(I N V, N I)$ & $\left(y_{i}^{c}, z_{j}\right)$ \\
$\Lambda_{8}$ & $(E)$ & $(N I, I N V)$ & $\left(z_{i}, y_{j}^{c}\right)$ \\
$\Lambda_{9}$ & $(B)$ and $(C)$ & $(I N V, N I)$ and $(N I, I N V)$ & $\left(y_{i}^{a}\left(z_{j}\right)-W_{i} / 2, z_{j}\right)$ and \\
$\Lambda_{10}$ & $(F)$ & $(N I, N I)$ & $\left(z_{i}, y_{j}^{a}\left(z_{i}\right)-W_{j} / 2\right)$ \\
\hline & & & $\left(z_{i}, z_{j}\right)$ \\
\hline
\end{tabular}

The firms' equilibrium behavior in the capacity game is illustrated in Figure 4. For the sake of exposition, we will assume that both firms have identical costs in the following discussion. Roughly speaking, if both have low existing capacities in comparison with expected future demand, i.e., $\left(z_{i}, z_{j}\right) \in \Lambda_{1}$, then there is an equilibrium $(I N V, I N V)$ in which they prefer to expand their capacity levels; if there is high existing capacity in comparison with expected future demand, i.e., $\left(z_{i}, z_{j}\right) \in \Lambda_{10}$, then there is an equilibrium $(N I, N I)$ in which they prefer not to invest; and if, in comparison with expected future demand, one firm has relatively low existing capacity but the other firm has relatively high existing capacity, i.e., $\left(z_{i}, z_{j}\right) \in \Lambda_{7}$ or $\Lambda_{8}$, then there is an equilibrium (INV,NI) or $(N I, I N V)$ in which one firm prefers to invest but the other prefers not to invest. 

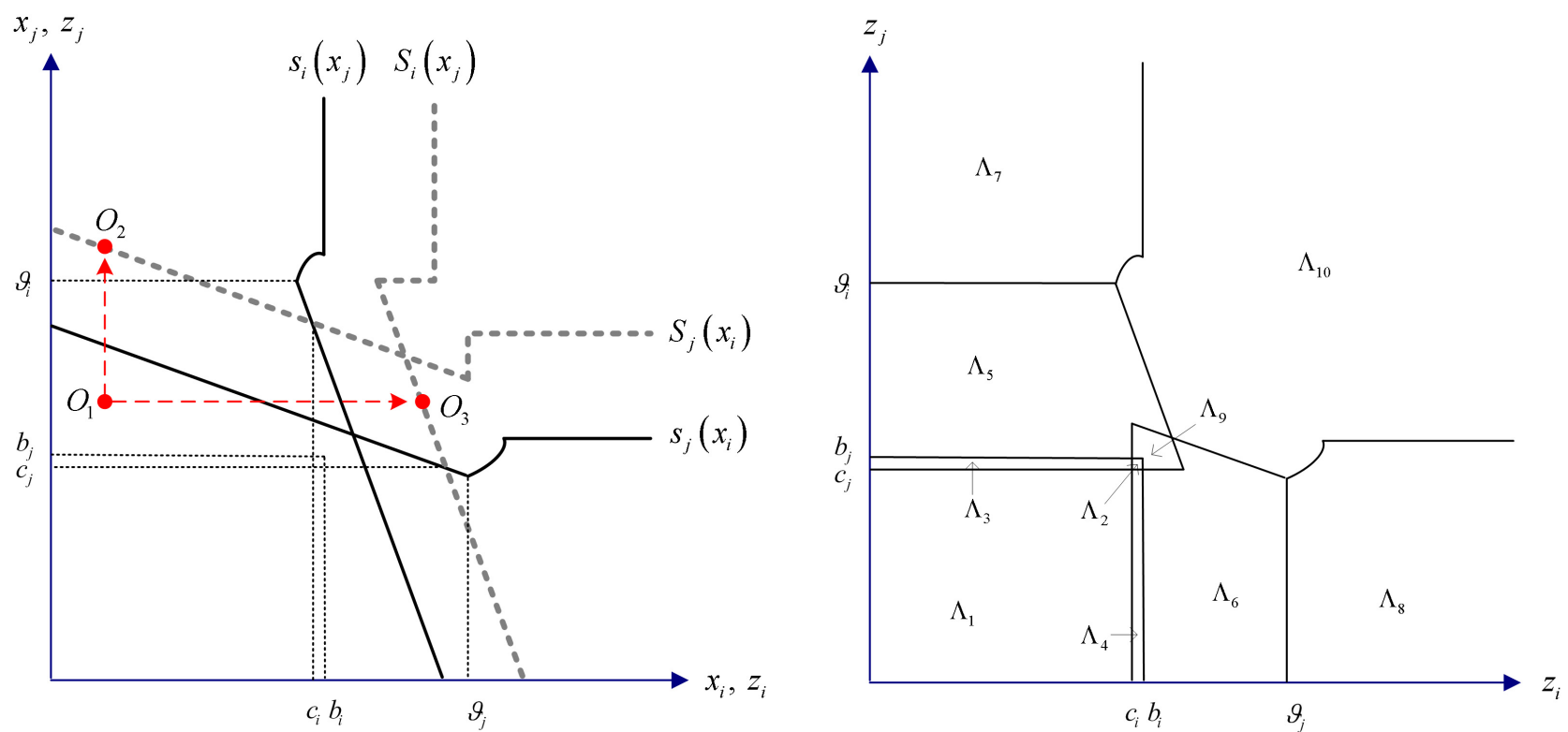

Figure 4: Mapping of Existing Capacity Pair onto Investment Equilibria

To help understand the way that the regions in Table 1 arise from the expansion point and the expansion level functions, we consider the point marked $O_{1}$ in Figure 4 . What are the possible equilibrium outcomes if $\left(z_{i}, z_{j}\right)=O_{1}$ ? The possibility of neither firm investing is ruled out because $z_{j}<s_{j}\left(z_{i}\right)$ (and also $z_{i}<s_{i}\left(z_{j}\right)$ ), so that either firm not investing would cause the other to decide to invest. Also the possibility of both firms investing is ruled out because $z_{j}>b_{j}$. If both firms were to invest then they should make $x_{i}=x_{i}^{C}$ and $x_{j}=x_{j}^{C}$. However, if firm $j$ knows that firm $i$ will have capacity $x_{i}^{C}$, then the investment cost will not be worthwhile since $z_{j}>b_{j}=s_{j}\left(x_{i}^{C}\right)$. So we can deduce that in an equilibrium, only one firm will invest. If firm $j$ invests but firm $i$ does not, then we will end at the point $\left(x_{i}, x_{j}\right)=O_{2}$. But, this cannot be an equilibrium since at point $O_{2}$ firm $i$ would choose to invest because $x_{i}$ is below its expansion point. On the other hand, if firm $i$ invests but firm $j$ does not, then we will end at the point $\left(x_{i}, x_{j}\right)=O_{3}$. This is a possible equilibrium outcome, (INV, $N I)$, since we have $z_{j}=x_{j}>s_{j}\left(x_{i}\right)$ at this point and so knowing the value of $x_{i}$ firm $j$ would choose not to invest.

Notice that in this case (and more generally if $\left(z_{i}, z_{j}\right) \in \Lambda_{5}$ or $\left.\Lambda_{6}\right)$ the weak firm, with lower existing capacity, can expand its capacity level and force its competitor (with higher existing capacity) not to invest, because the other firm cannot get enough revenue to cover its investment expenditure if both of them were to invest. The strong firm, with higher existing capacity, finds it not worthwhile to make an additional investment facing the aggressive challenger, and the challenger (firm $i$ ) finally obtains a larger market share.

Our next result relates to the similarity between holdback and clearance in an equilibrium environment. We will return to this issue in Section 6. Suppose that firm $i$ invests in additional capacity and in the production stage of the game does not use all its capacity. Then a small reduction in investment will not effect the production amounts and will result in reduced investment costs and an improved profit. Hence we obtain the following result (which can also be checked directly by considering the production quantities that occur in the different regions in Table 1). 
Lemma 4. Suppose that there is an equilibrium in which firm $i$ invests in additional capacity, then at the production stage firm $i$ will set its production level equal to its capacity.

\subsection{Multiple equilibria}

When $\left(z_{i}, z_{j}\right) \in \Lambda_{2}, \Lambda_{3}, \Lambda_{4}$, or $\Lambda_{9}$, multiple equilibria occur in the capacity game. The obvious problem with multiple equilibria is that the firms may not foresee which equilibrium will prevail. Mahajan and van Ryzin (2001) argue that a symmetric equilibrium is more reasonable than an asymmetric equilibrium according to the focal point effect proposed by Schelling (1960). Thus, in our case (INV, $I N V)$ is a more likely equilibrium than $(I N V, N I)$ and $(N I, I N V)$ for $\left(z_{i}, z_{j}\right) \in \Lambda_{2}$. But, there exists no symmetric equilibrium for $\left(z_{i}, z_{j}\right) \in \Lambda_{3}, \Lambda_{4}$, or $\Lambda_{9}$, in which each firm would prefer a different equilibrium, for example firm $i$ prefers $(I N V, N I)$ over $(N I, I N V)$. Hence, it is possible that a non-equilibrium outcome results since firm $i$ plays one equilibrium strategy of $(I N V, N I)$ while firm $j$ chooses the other equilibrium strategy of $(N I, I N V)$. However, if there exists some process of preplay communication then Schelling argues that the players could become focused on one equilibrium. For instance, if firm $i$ can convince firm $j$ of its persistence in the $I N V$ strategy we might well expect them to play $(I N V, N I)$. See Cachon and Netessine (2004) for a discussion of the implications of multiple equilibria in game theory models of operations and supply chain.

On the other hand if there are no fixed costs, the multiple equilibrium regions, $\Lambda_{2}, \Lambda_{3}, \Lambda_{4}$, and $\Lambda_{9}$, disappear since the expansion point and the expansion level functions are identical (i.e., $s_{i}(\cdot)=S_{i}(\cdot)$ when $K_{i}=0$ ). Thus setting $K_{i}=K_{j}=0$, Theorem 2 implies:

Corollary 1. In a production holdback environment with no fixed costs of investment, there always exists a unique SPNE for any existing capacities $\left(z_{i}, z_{j}\right)$.

In other words, the existence of fixed costs adds more strategic uncertainty in the capacity game, as suggested by Porter (1980). If there are no clues prior to starting the game (i.e., preplay communication), both firms may simultaneously play the $I N V$ strategy aiming for an equilibrium in which the other player does not invest. This can happen for $\left(z_{i}, z_{j}\right) \in \Lambda_{2}, \Lambda_{3}, \Lambda_{4}$ or $\Lambda_{9}$ when scale economies in investment are significant, and will imply some industry excess capacity. The examples we give in section 5.3 confirm that this is not just a theoretical possibility.

Remark 1. When there are fixed costs of investment, for certain existing capacities in the capacity game there may be either multiple equilibria, or no equilibrium.

\subsection{Production versus investment costs}

This formulation also allows us to investigate the consequences of sunk investment costs (represented by $W_{i}$ ). We expect that when costs are moved away from the production decision (represented by $V_{i}$ ) and instead are incurred at the time of investment (represented by $W_{i}$ ) then this will enable the investing firm to demonstrate greater commitment - hence allowing more effective preemptive investment strategies in the holdback environment. For example, this could happen if firm $i$ was to commit to purchase raw materials at the same time as building capacity; or if firm $i$ was to choose a higher level of automation. If this effect occurs, we can expect that the region where firm $j$ is able to 
gain from investing, even though firm $i$ has already built a large capacity, will be reduced. In other words, we expect that the region including $\Lambda_{6}$ and $\Lambda_{8}$ will be reduced. Formally,

Corollary 2. Suppose that Assumptions 2 and 3 hold and suppose that $V_{i}$ and $W_{i}$ are changed as follows: $V_{i}^{\text {new }}=V_{i}-\Delta$ and $W_{i}^{\text {new }}=W_{i}+\Delta$. Then, the region $\Lambda_{6} \cup \Lambda_{8}$ decreases as $\Delta$ increases.

Proof. To complete this proof, we consider moving a cost $\Delta$ from $V_{i}$ to $W_{i}$, so $V_{i}^{\text {new }}=V_{i}-\Delta$ and $W_{i}^{n e w}=W_{i}+\Delta$. It is easy to see that this increases the Cournot equilibrium amount $y_{i}^{c}$ by an amount $2 \Delta / 3$ and decreases $y_{j}^{c}$ by an amount $\Delta / 3$. Hence $\vartheta_{j}$ increases. Note that $y_{i}^{a}\left(x_{j}\right)$ is increased by $\Delta / 2$ and so both $s_{i}^{L}(\cdot)$ and $S_{i}^{L}(\cdot)$ are unchanged. Moreover $S_{j}^{L}(\cdot)$ is unchanged, so $c_{i}$ will also be unchanged. Finally observe that $s_{j}^{B}$ decreases since $y_{j}^{c}$ decreases and

$$
\frac{\partial s_{j}^{B}}{\partial y_{j}^{c}}=\frac{3}{2}-\frac{y_{j}^{c} / 2-W_{j}}{\sqrt{2 K_{j}+\left(y_{j}^{c} / 2-W_{j}\right)^{2}}}>0 .
$$

It is straightforward to see from Figure 4 that the net effect is to reduce $\Lambda_{6} \cup \Lambda_{8}$, since we have extended $\Lambda_{6}$ to the right and reduced the horizontal upper boundary of $\Lambda_{8}$ (which is at $s_{j}^{B}$ ).

We can also investigate the effect of moving a cost from $V_{i}$ to $W_{i}$ on firm $i$ 's profit. Using simple algebra (see the on-line supplementary material), we obtain:

Remark 2. In a production holdback environment, the ability of a firm to preempt an entering firm can be strengthened by moving a cost from the variable cost of production to the variable cost of investment. Profits for the incumbent will be increased except in cases where there is a large excess initial capacity.

As Porter notes (1980: 101): 'Perhaps the single most important concept in planning and executing offensive and defensive competitive moves is the concept of commitment. ... The persuasiveness of a commitment is related to the degree to which it appears binding and irreversible.' Previous models have usually treated capacity commitment as employing a production clearance strategy. These results show that in this environment a type of commitment can occur that arises from the structure of the costs of investment and production, even though there cannot be any binding or irreversible determination of the future production level. Furthermore this type of commitment, achieved by advancing production costs, will have a positive impact on firm performance if there is not too large an excess capacity. This is a new observation in model-based capacity strategy research (Ghemawat and Cassiman, 2007). This analytical finding fits the empirical observations in competitive strategy (Chen et al., 2002) and suggests that, in a production holdback environment, a firm may benefit from investing in production lines involving higher investment cost but lower operating costs (for example through opting to use a higher degree of automation).

\subsection{Examples of Asymmetric Firms}

Our model allows us to consider cases with asymmetric costs between firms. We illustrate how our theoretical results apply to asymmetric cases by exploring the following three examples to gain additional insights. It is noted that all of the examples satisfy Assumption 2. 
Example 1. There are two firms in a concentrated market, firm 1 with a high cost technology and firm 2 with a low cost technology. The firms have cost functions: $V_{1}=1, W_{1}=1.4$ and $K_{1}=6$ for firm 1 , and $V_{2}=0.5, W_{2}=1$ and $K_{2}=3$ for firm 2 . Demand is characterized by $A=10$.
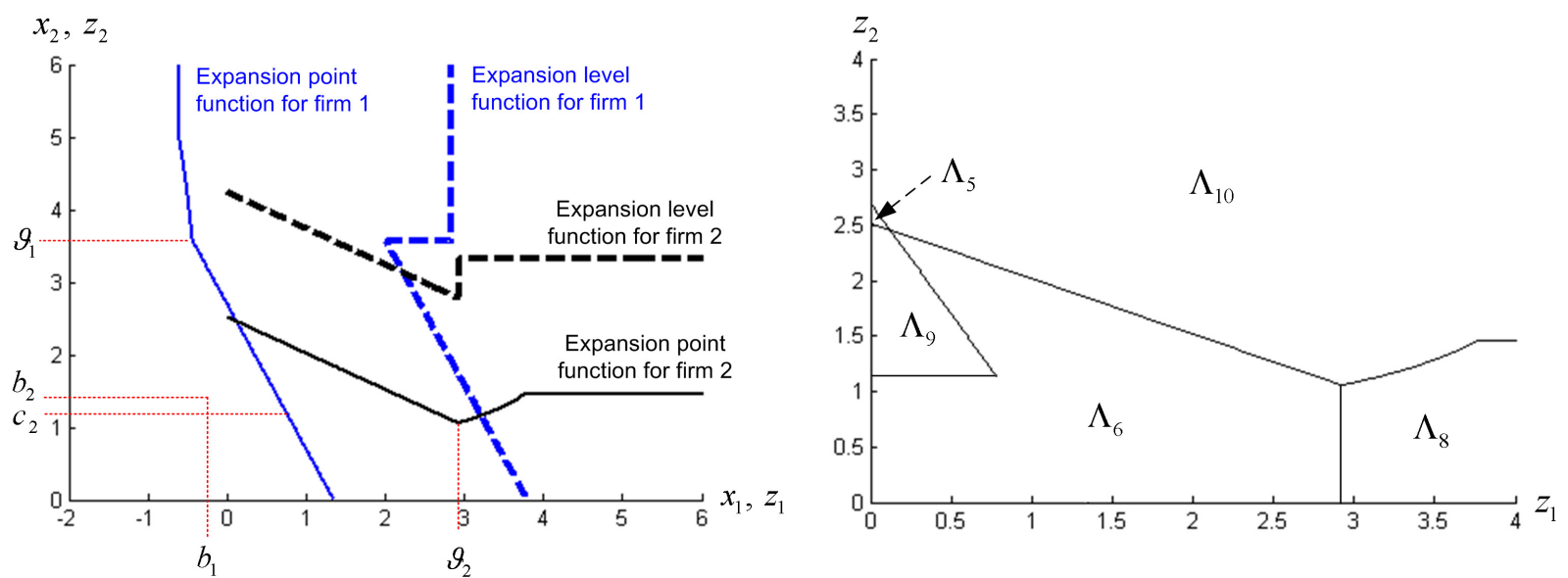

Figure 5: Example 1 for Asymmetric Duopoly

Applying Theorem 2, we can show the equilibrium behavior of investment for the first example in Figure 5. Except for $\left(z_{1}, z_{2}\right) \in \Lambda_{5} \cup \Lambda_{9}$, firm 1 will never invest in additional capacity. According to the definition of region $\Lambda_{9}$, firm 2 also has a chance to invest for $\left(z_{1}, z_{2}\right) \in \Lambda_{9}$. So in this region there are two possible equilibria. This equilibrium outcome for $\left(z_{1}, z_{2}\right) \in \Lambda_{9}$ is similar to the famous battle-of-the-sexes outcome. Only if there exists a focal point effect such as preplay communication may we have an expectation on which asymmetric equilibrium will occur. The example implies that a firm with significant cost advantage over the other will choose to invest even if the firm has no existing capacity and its competitor owns high existing capacity, i.e., $\left(z_{1}, z_{2}\right) \in \Lambda_{6} \cup \Lambda_{8}$. Thus, in this instance building excess capacity is not a good strategy for an incumbent with a cost disadvantage. This is because the production holdback environment does not allow the incumbent to commit to full production, and so building excess capacity does not provide a credible commitment. This outcome is similar to the well-known example of the steel industry, where leading integrated steel mills proved to have no incumbent advantage upon encountering the challenge from entering minimills with a disruptive technology of production (e.g., Christensen, 1997).

Example 2. The parameters in this example are the same as for example 1, except we take $K_{1}=0$, that is, the incumbent (firm 1) has an incumbent advantage in that its fixed cost has already been spent (or sunk). We leave other parameters unchanged. Therefore, firm 1 has an expansion point function that is the same as its expansion level function. The equilibrium behavior of investment in this example is shown in Figure 6. If the incumbent's existing capacity is small in comparison with expected demand, i.e., $\left(z_{1}, z_{2}\right) \in \Lambda_{1}$, the incumbent and the entrant (firm 2) will invest simultaneously. In this example, condition (4) does not hold since $x_{1}^{c}>\vartheta_{2}$ so there is no equilibrium for the existing capacity pairs in the region we have labeled $\Lambda_{0}$. For $\left(z_{1}, z_{2}\right) \in \Lambda_{0}, z_{1}$ is below firm 1's expansion point but $z_{2}$ is above firm 2's expansion point. Following Theorem 1, firm 1 would like to invest such that $\left(x_{1}, z_{2}\right) \in \Lambda_{8}$ and firm 2 chooses not to invest. After firm 1's investment decision, firm 2 will invest its 

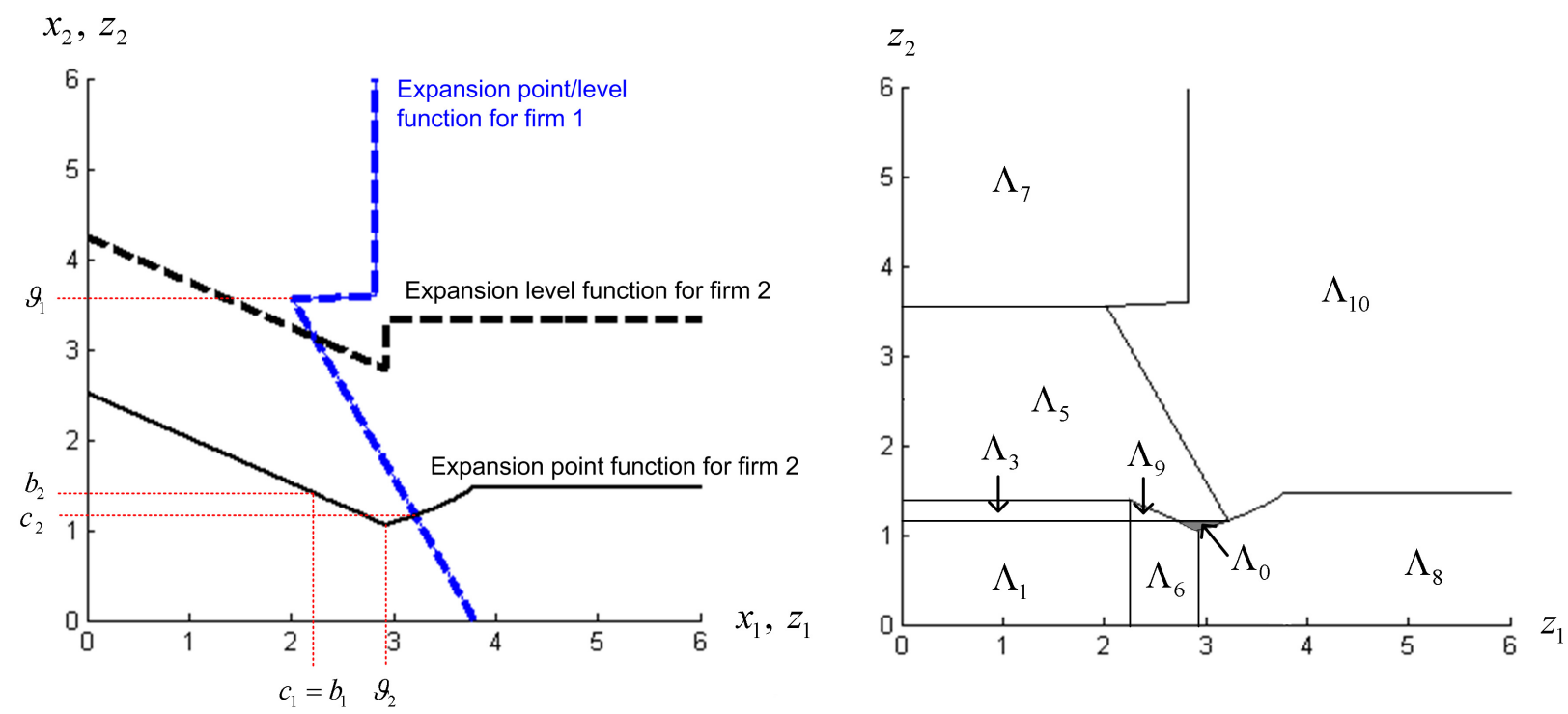

Figure 6: Example 2 for Asymmetric Duopoly

capacity level up to $y_{2}^{c}$. Therefore, there is no equilibrium for any $\left(z_{1}, z_{2}\right) \in \Lambda_{0}$.
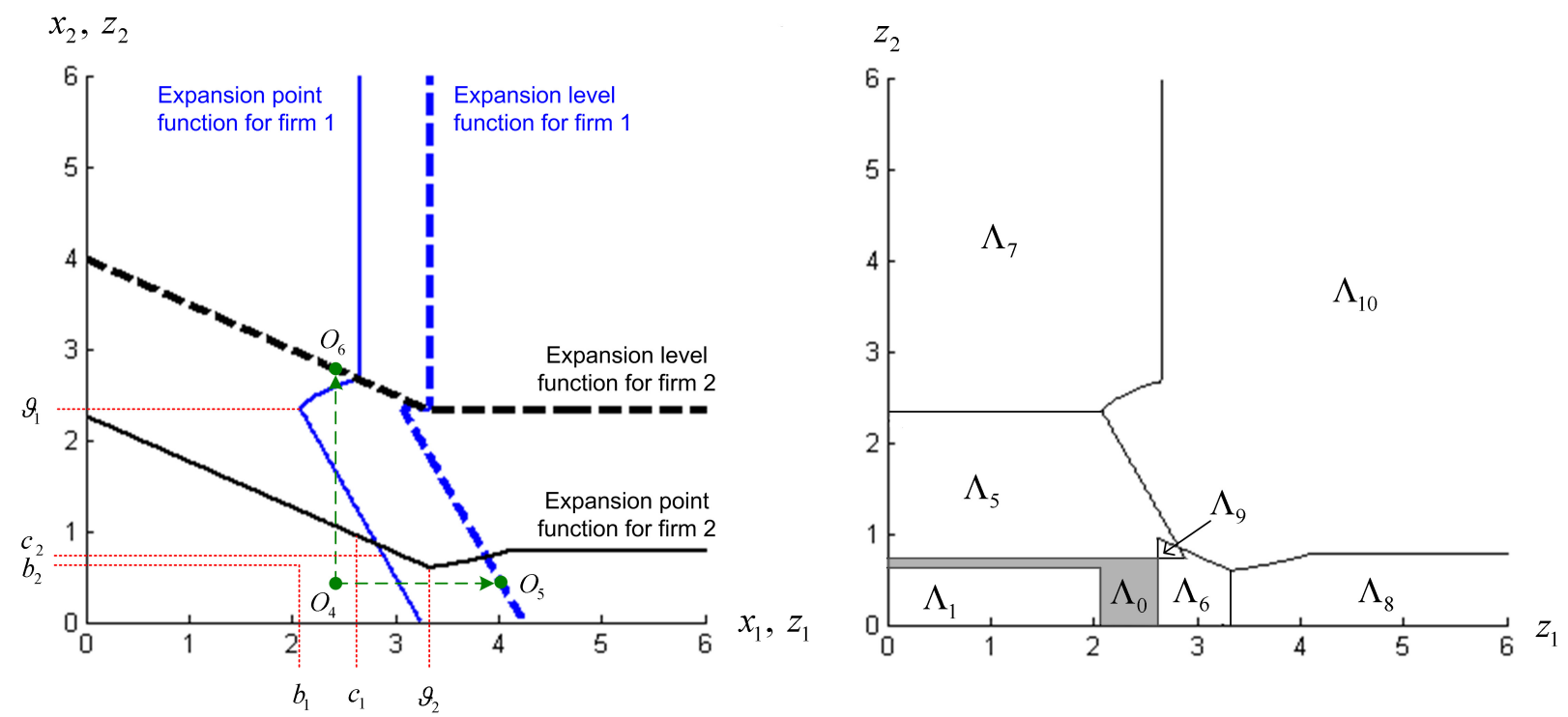

Figure 7: Example 3 for $b_{i}<c_{i} \forall i$

Example 3. Finally, consider an example shown in Figure 7 for which the firms have cost functions: $V_{1}=1, W_{1}=0.5$ and $K_{1}=1$ for firm 1 and $V_{2}=2, W_{2}=0.01$ and $K_{2}=3$ for firm 2 , and the demand intercept $A$ is 10 . In this instance, condition (3) does not hold and there is no equilibrium for the existing capacities in the shaded region we label $\Lambda_{0}$. To help in understanding why there is no equilibrium in region $\Lambda_{0}$, we look at point $O_{4}$. At point $O_{4}, z_{1}$ and $z_{2}$ are both below their expansion points so that $(N I, N I)$ is not an equilibrium outcome. If firm 1 invests but firm 2 does not, we move to point $O_{5}$. But, at point $O_{5}$ firm 2 would choose to invest because $z_{2}$ is below its expansion point. Hence, point $O_{5}$ is not an equilibrium outcome. On the other hand, if firm 2 invests but firm 1 does not, then we move to point $O_{6}$. At point $O_{6}$, firm 1 would choose to invest because $z_{1}$ is below its 
expansion point. Thus, neither $(I N V, N I)$ nor $(N I, I N V)$ is an equilibrium outcome for point $O_{4}$. In addition, $(I N V, I N V)$ is not an equilibrium outcome since $z_{1}>b_{1}$ and so firm 1 would decide not to invest if $x_{2}=x_{2}^{C}$.

\subsection{When can strategic deterrence occur?}

The examples given above have demonstrated that building excess capacity may not to be an effective strategy for an incumbent to deter the potential entrant from investing in capacity under the production holdback environment. The ineffectiveness of excess capacity by firm $i$ is related to the fact that for low values of $z_{j}$ no matter how large $z_{i}$ becomes, the investment equilibria falls into $\Lambda_{8}$ where firm $j$ invests. The condition for this to happen is that $s_{j}^{B}>0$, i.e.,

$$
\frac{3}{2} y_{j}^{c}-W_{j}>\sqrt{2 K_{j}+\left(\frac{y_{j}^{c}}{2}-W_{j}\right)^{2}} .
$$

This inequality reduces to $K_{j}<y_{j}^{c}\left(y_{j}^{c}-W_{j}\right)$. Thus we have shown that only when the fixed cost of investment for the other firm is larger than a certain threshold, $y_{j}^{c}\left(y_{j}^{c}-W_{j}\right)$, will it be possible for an incumbent to invest aggressively in order to eliminate a potential rival from entering a market.

This discussion demonstrates that excess capacity will often not be an effective strategy when symmetric-cost firms employ holdback in production. We therefore would not expect to see an excesscapacity strategy in a competitive environment in which firms are able to use holdback in their production. This result seems to be supported by empirical observations made by Lieberman (1987c), who looked at the chemical industry over a roughly 25 year period and found that excess capacity was very rarely used as an entry deterrent.

\subsection{Equilibrium with Cost Parity}

In this section we will simplify our analysis to isolate the strategic issues governing capacity investment decisions. We wish to eliminate the effects of asymmetric costs and so we will assume that all capacity and production costs for firms are identical, i.e., cost parity, as does Anand and Girotra (2007). This will allow us to omit the subscripts of parameters and functions in Theorems 1 and 2 in the following.

The cost parity makes $x^{C}<\vartheta$. Without loss of generality, we can adjust the price $A$ and normalize the production costs to zero $\left(V_{i}=V_{j}=V=0\right)$. In addition, the following assumption is imposed to avoiding the trivial case where the expansion point functions are negative (i.e., both firms never invest).

Assumption 4. $K<A(A-3 W) / 9$.

This assumption together with Assumption 2 make $x^{C}>x^{s}>0$ and condition (4) holds. However, condition (3) may or may not hold here, depending on the magnitude of the fixed cost; thus the multiple equilibrium regions $\Lambda_{2}, \Lambda_{3}$ and $\Lambda_{4}$ may exist or not. The capacity equilibrium behavior under cost parity is shown in Figure 8. We can see that when $z_{j}=0$, firm $j$ will enter the market if either $\left(z_{i}, 0\right) \in \Lambda_{1}, \Lambda_{4}, \Lambda_{6}$ or $\Lambda_{8}$ in Figure 8(a) or $\left(z_{i}, 0\right) \in \Lambda_{1}, \Lambda_{6}$ or $\Lambda_{8}$ in Figure 8(b). Note that there does not exist any equilibrium in the capacity game if $\left(z_{i}, 0\right) \in \Lambda_{0}$, shown in Figure $8(\mathrm{~b})$. 


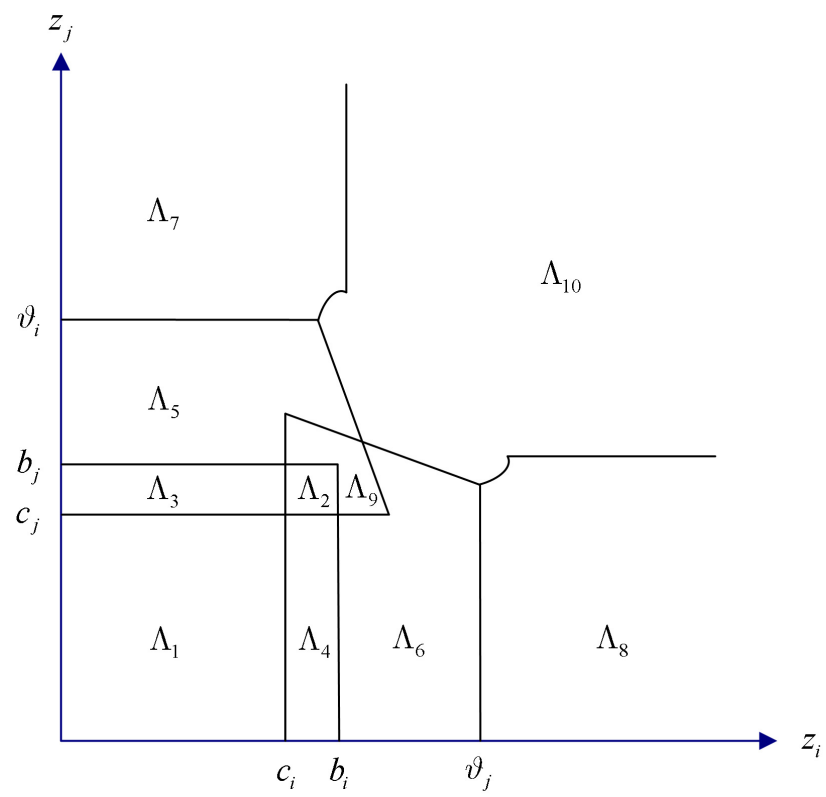

(a) Condition 3 holds

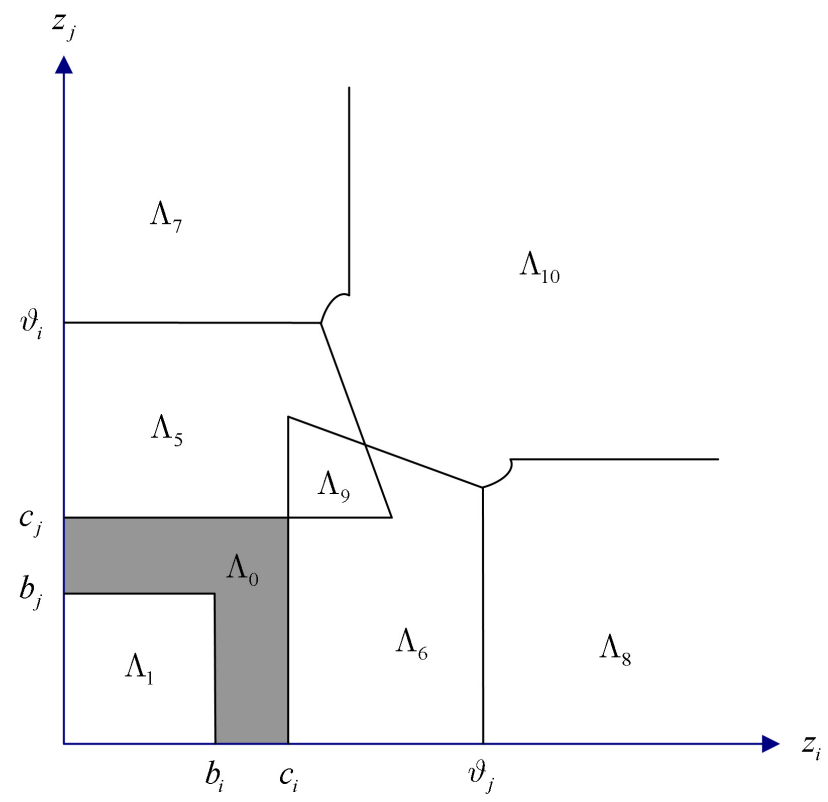

(b) Condition 3 does not hold

Figure 8: Capacity Equilibrium under Holdback Production and Cost Parity

Finally, the simplest case occurs when we set the fixed cost $K$ to zero and leave other parameters unchanged. In this setting, Assumption 2 makes $0<x^{C}<\vartheta$ so that $b=c=x^{C}$. We find that the equilibrium regions $\Lambda_{l}, l=1,5,6,7,8,10$, cover the entire $\left(z_{i}, z_{j}\right)$ space, shown in Figure 9.

\section{Two alternative models}

So far our analysis has relied on two presumptions that we will relax in this section: first that the holdback strategy is available in production, and second that in the first stage capacity decisions are made simultaneously due to the long lead time. Section 6.1 studies the competitive environment when holdback is not possible; and Section 6.2 analyzes alternating capacity decisions - where one firm invests first and the other invests later. This alternating scheme is simpler than the model of simultaneous capacity decisions. By investigating it we want to find out whether the holdback (or clearance) strategy has the same impact on the equilibrium behavior in the sequential-decision scheme as it does in the simultaneous-decision scheme?

\subsection{Clearance in Production}

In order to understand the difference between employing holdback and clearance, we now analyze investment equilibrium behavior in a simultaneous-move game assuming that firms use clearance as a production strategy (so that firms make decisions on capacity and production at the same time). This is an assumption that has been made by most model-based literature on competitive capacity investment.

From Lemma 4 we know that in the event that both firms choose to invest, then the clearance 


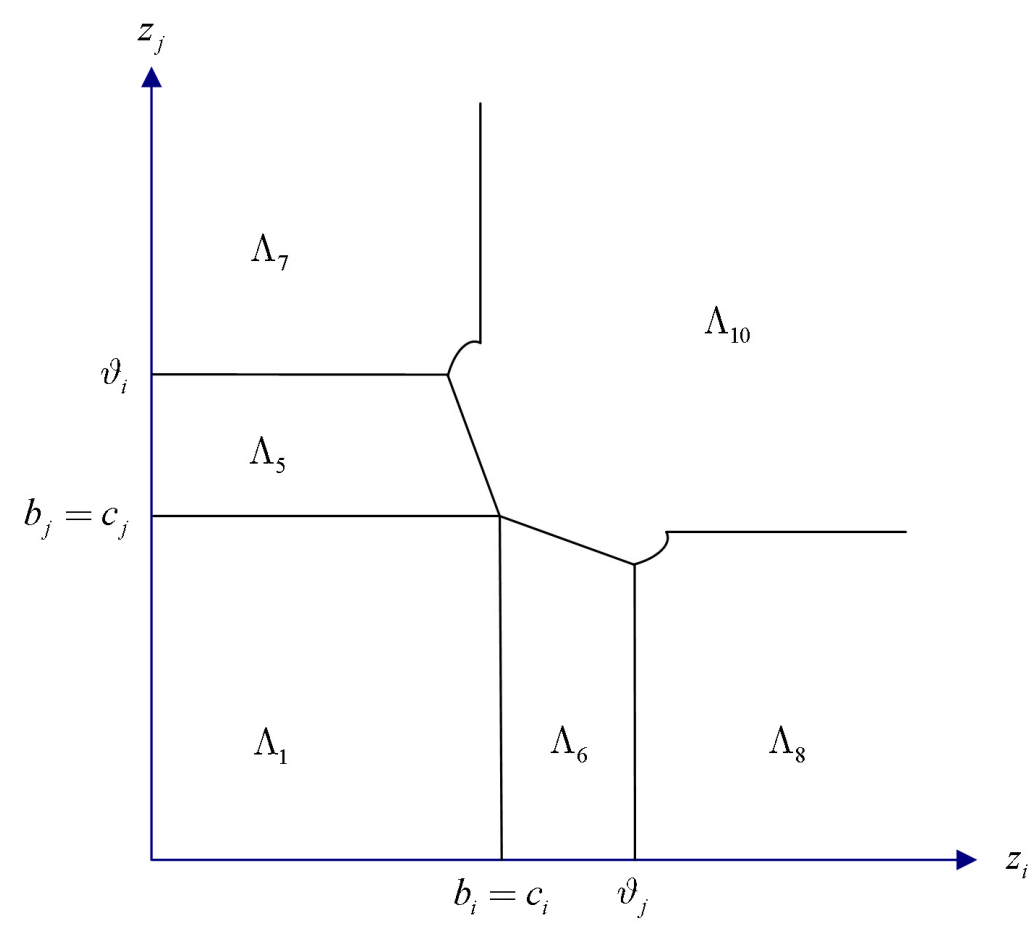

Figure 9: Capacity Equilibrium under Holdback Production, Cost Parity and Zero Fixed Costs and holdback strategies will be the same. However, we will see that there are substantial differences in behavior when one firm has excess capacity.

The solutions in the clearance case will involve the simpler functions $s_{i}^{L}, s_{j}^{L}, S_{i}^{L}$ and $S_{j}^{L}$ rather than $s_{i}, s_{j}, S_{i}$ and $S_{j}$. This allows us to be more explicit. We define

$$
\begin{aligned}
b_{i}^{L} & =s_{i}^{L}\left(x_{j}^{C}\right)=y_{i}^{a}\left(x_{j}^{C}\right)-\frac{W_{i}}{2}-\sqrt{K_{i}} \\
& =x_{i}^{C}-\sqrt{K_{i}} .
\end{aligned}
$$

Also we have $c_{i}^{L}=s_{i}^{L}\left(S_{j}^{L}\left(c_{i}^{L}\right)\right)$ from which we deduce

$$
c_{i}^{L}=x_{i}^{C}-\frac{4}{3} \sqrt{K_{i}}
$$

(with matching expressions for $b_{j}^{L}$ and $c_{j}^{L}$ ). We can establish the following result for the firms' capacity equilibrium in pure strategies:

Theorem 3. Suppose that Assumption 2 holds and both firms use a production clearance strategy. Then,

(i) the investment pair $(I N V, I N V)$ with $\left(x_{i}, x_{j}\right)=\left(x_{i}^{C}, x_{j}^{C}\right)$ is a SPNE in the capacity game if and only if the existing capacities satisfy the conditions $z_{i}<b_{i}^{L}$ and $z_{j}<b_{j}^{L}$;

(ii) the investment pair $(I N V, N I)$ with $\left(x_{i}, x_{j}\right)=\left(S_{i}^{L}\left(z_{j}\right), z_{j}\right)$ is a SPNE in the capacity game if and only if the existing capacities satisfy the conditions $z_{i}<s_{i}^{L}\left(z_{j}\right)$ and $z_{j} \geq c_{j}^{L}$ (and a matching result for the investment pair (NI,INV) with $i$ and $j$ reversed); 
(iii) the investment pair $(N I, N I)$ with $\left(x_{i}, x_{j}\right)=\left(z_{i}, z_{j}\right)$ is a SPNE in the capacity game if and only if the existing capacities satisfy the conditions $z_{i} \geq s_{i}^{L}\left(z_{j}\right)$ and $z_{j} \geq s_{j}^{L}\left(z_{i}\right)$.

Proof. Under a production clearance environment, $x_{i}=y_{i}$ and $x_{j}=y_{j}$. Then, we can write

$$
\pi_{i}^{L}\left(x, x_{j}\right)=\left(A-V_{i}-x-x_{j}\right) x
$$

for the operational profit of firm $i$ in production. Given the rival's investment decision $x_{j}$, the optimal profit of firm $i$ in the capacity game can be written:

$$
\Pi_{i}^{L}\left(z_{i}, x_{j}\right)= \begin{cases}\pi_{i}^{L}\left(S_{i}^{L}\left(x_{j}\right), x_{j}\right)-W_{i}\left(S_{i}^{L}\left(x_{j}\right)-z_{i}\right)-K_{i} & \text { for } z_{i}<s_{i}^{L}\left(x_{j}\right), \\ \pi_{i}^{L}\left(z_{i}, x_{j}\right) & \text { otherwise. }\end{cases}
$$

Here $\left(A-V_{i}-W_{i}-x_{j}\right) / 2$ is the unique maximizer of function $\left\{\pi_{i}^{L}\left(x, x_{j}\right)-W_{i}\left(x-z_{i}\right)\right\}$ for each $x_{j}$ and is equal to $S_{i}^{L}\left(x_{j}\right)$. In this case, $S_{i}^{L}\left(x_{j}\right)$ exists because $\pi_{i}^{L}$ is strictly concave in its first argument. The smallest value of $v$ for which

$$
\pi_{i}\left(v, x_{j}\right)-W_{i}\left(v-z_{i}\right)=\pi_{i}\left(S_{i}^{L}\left(x_{j}\right), x_{j}\right)-W_{i}\left(S_{i}^{L}\left(x_{j}\right)-z_{i}\right)-K_{i}
$$

is $\left(A-V_{i}-W_{i}-x_{j}\right) / 2-\sqrt{K_{i}}$ which is equal to $s_{i}^{L}\left(x_{j}\right)$. Thus we have established that firm $i$ 's optimal policy of investment for given $x_{j}$ is as follows:

$$
\bar{x}_{i}\left(x_{j}\right)=\left\{\begin{array}{cl}
S_{i}^{L}\left(x_{j}\right) & \text { for } z_{i}<s_{i}^{L}\left(x_{j}\right) \\
z_{i} & \text { otherwise. }
\end{array}\right.
$$

This is to be compared with Theorem 1 and can be used to prove the result in the same way that Theorem 2 was established.

Consider case (ii) when $z_{i}<s_{i}^{L}\left(z_{j}\right)$ and $z_{j} \geq c_{j}^{L}$. Under these conditions the optimal response for firm $i$ to firm $j$ not investing is to invest up to a capacity level of $S_{i}^{L}\left(z_{j}\right)$. On the other hand if $z_{j} \geq c_{j}^{L}$ then $z_{j} \geq s_{j}\left(S_{i}^{L}\left(z_{j}\right)\right)$ and hence the optimal response for firm $j$ to this investment by firm $i$ is not to invest. In the other direction if $\left(x_{i}, x_{j}\right)=\left(S_{i}^{L}\left(z_{j}\right), z_{j}\right)$ is a SPNE in the capacity game then we derive the conditions $z_{i}<s_{i}^{L}\left(z_{j}\right)$ and $z_{j} \geq s_{j}\left(S_{i}^{L}\left(z_{j}\right)\right)$ immediately.

The other two cases follow similarly.

Since $b_{i}^{L} \geq c_{i}^{L}$, with equality when the fixed $\operatorname{cost} K_{i}=0$ we can deduce the following corollary:

Corollary 3. In the production clearance environment, there exists at least one SPNE for each pair of existing capacities, and if there are no fixed costs of investment, then this SPNE is unique.

Figure 10 shows the equilibrium behavior in a case where there is cost parity $\left(V_{i}=V_{j}, W_{i}=W_{j}\right.$, and $K_{i}=K_{j}$ ). This figure demonstrates that when $z_{j}=0$, firm $i$ can deter firm $j$ 's entry provided that firm $i$ has sufficient existing capacity such that $\left(z_{i}, 0\right) \in \Lambda_{10}^{L}$. Specifically we can see that, whether or not there is cost parity, $x_{j}=z_{j}=0$ is the equilibrium outcome for $z_{i}>\left(s_{i}^{L}\right)^{-1}(0)$. We can summarize:

Remark 3. For an incumbent facing a potential entrant in a production clearance environment, strategic preemption with a large amount of existing capacity can deter the entrant. 


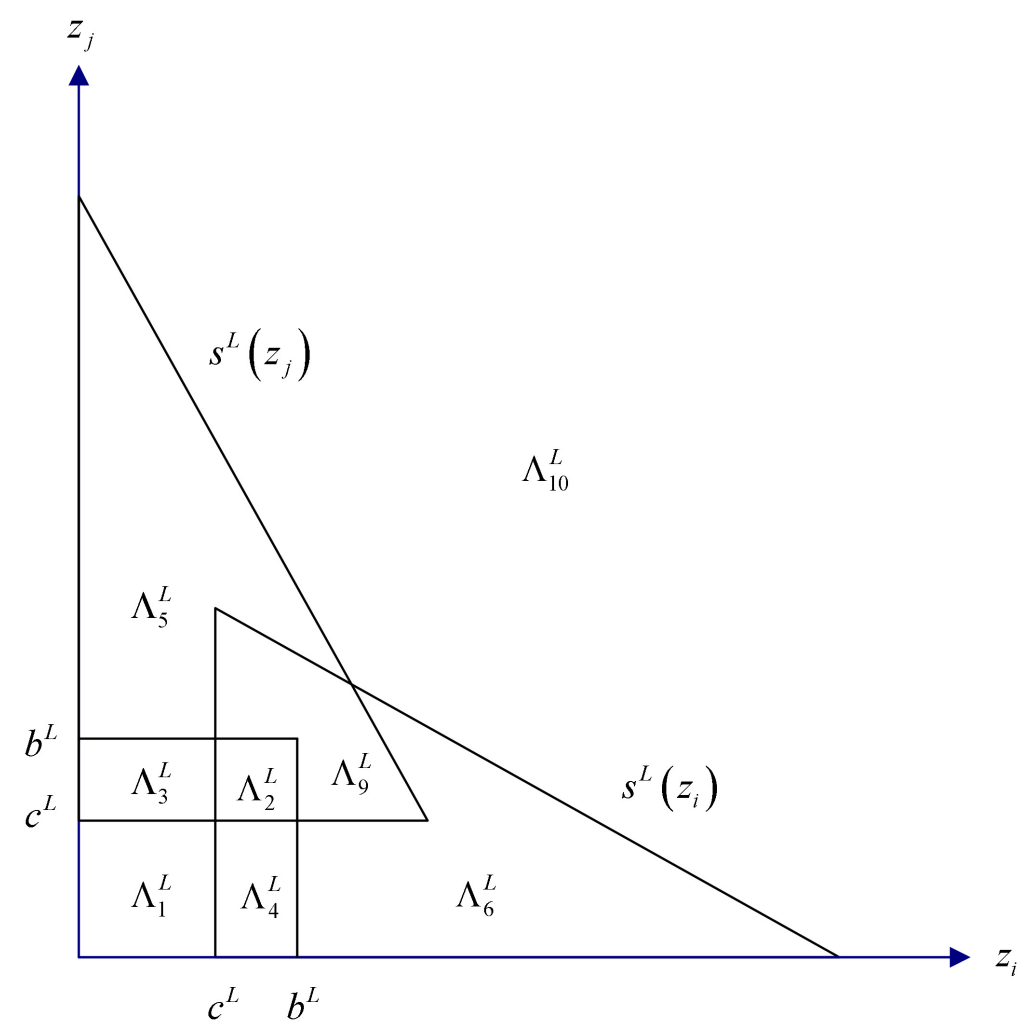

Figure 10: Capacity Equilibrium under Clearance Production and Cost Parity

In general the production clearance environment is more favorable for the incumbent and less favorable for the potential entrant in comparison with the holdback environment. In the online supplementary material we analyze in more detail the case that the fixed costs are zero and where firm $i$ is an entrant with $z_{i}=0$ and firm $j$ is an incumbent with $z_{j}>\vartheta_{i}$, and we show that in this case profitability for the incumbent is greater with a clearance environment. Other cases are similar.

By comparing the overall profits arising from holdback and clearance, we obtain:

Remark 4. A production clearance environment gives more profit for the incumbent and less profit for the potential entrant.

\subsection{Alternating Investment Decisions}

In this section, we consider an alternative capacity-decision scheme that of two firms making investment decisions sequentially, as is often assumed in the commitment literature (see Tirole, 1988). We thus assume that the lead time (or at least time to commit to a certain capacity) is short enough to enable the leading firm to have completed this stage prior to its rival's investment decision. This makes the analysis much easier compared to the simultaneous decision scheme. Assume that firm $i$ is a leader, firm $j$ is a follower, and both have no capacity ex ante $\left(z_{i}=z_{j}=0\right)$. As in Section 5.2, we assume identical costs between the firms in order to isolate the industry issues related to the impacts of holdback and clearance production. Moreover, we take $V_{i}=V_{j}=0$ without loss of generality.

In addition to analytical simplicity, another useful property of this decision scheme is that we can ignore the effect of fixed costs without loss of generality. Specifically, the leader can easily evaluate 
whether the entrant enters the market or not by deducting the fixed cost from its revenue. If the entrant's net profit allowing for the fixed cost is positive, it enters; otherwise, it does not. Note that this property does not hold in the simultaneous decision scheme (see Remark 2). As a result, there are no issues of multiple equilibria and non-equilibrium in the sequential setting. Roughly speaking, there is less strategic uncertainty for a short lead time.

Through a careful analysis given in the on-line supplementary material, the following results are obtained.

Remark 5. The first-mover advantage always exists in the sequential setting no matter what production policy is employed.

Remark 6. No matter what the decision sequence (simultaneous or sequential move), holdback production always reduces the advantage of having more existing capacity, and clearance production reinforces the advantage.

\section{Conclusion}

This paper develops a game-theoretical model to analyze competitive responses for strategic capacity investment. In particular, we consider the joint effect of several operational characteristics including existing capacity, scale economies, lead time, and production policy on capacity investment in equilibrium. Each firm makes two decisions: choice of capacity and choice of production quantity. The capacity decision sequence (simultaneous or alternating) and production policy (holdback or clearance) are both determined by the competitive environment in which the firms operate. We develop the best response of the firms in the capacity decision and use it to develop the firms' equilibrium behavior for both simultaneous and sequential investment decisions. After introducing plausible assumptions, we are able to solve the entire game in closed form. One novel element in our model is that competing firms are able to have some existing capacity prior to the start of the competitive capacity investment decisions. Furthermore, our work differs from the capacity-related literature by explicitly considering the ex-ante asymmetries that exist in both existing capacities and investment costs. Our findings provide systematic answers to questions about how to restrain competitive responses to a capacity action:

1. The existing literature has shown that making simultaneous moves reduces the commitment implied by ex ante capacity in comparison with a sequential move, see Dixit (1980) and Tirole (1988). We confirm that this result holds under our setting as well, and further show that this effect of move sequence is much stronger for firms in a production clearance environment than in a holdback environment. In other words, the commitment value of ex ante capacity can be reduced when there are both a long lead time to build additional capacity and a production holdback environment. So, operational factors do matter to capacity strategy.

2. We show that in the production holdback environment, excess capacity cannot deter the entry of the potential competitor no matter how large the existing capacity of the incumbent firm. This is different to the clearance environment where an incumbent with sufficient capacity can 
deter entry. More generally, in the leader-follower game of capacity investment the first-mover advantage is greater in a clearance environment.

3. Under holdback production, our analytical result shows that the commitment represented by existing capacity can be strengthened by moving a cost from the variable cost of production to the variable cost of investment. This is an example of commitment being increased as the investment action involves more irreversibility (Chen and MacMillan, 1992; Hayes et al., 2005; Chronopoulos et al., 2011). In other words, an incumbent firm has a greater preemptive advantage if its production facilities involve higher investment cost but lower operational cost. Usually this leads to an improvement in the incumbent's profit (though this improved profit can be canceled out by the additional costs in building an initial excess capacity).

4. We find that in a production holdback environment fixed costs make the problem of simultaneous investment complicated in two different ways: first they introduce the possibility of multiple equilibria in investment competition, and second fixed costs mean that Nash equilibrium in pure strategies may not exist for some existing capacities. However, these complications only arise when the lead time is sufficiently long. In other words, fixed costs and long lead times increase strategic uncertainty (emerging endogenously from the strategic interactions between competing firms) as argued by Porter (1980). So strategic uncertainty is much greater than is suggested by previous studies that do not consider fixed costs and lead time.

These findings provide practical guidelines for competitive moves in capacity races. For firms in a production clearance environment, an incumbent may consider acting aggressively in investment in order to deter potential entrants, but should act more cautiously in order to maintain its market share facing another incumbent. These 'asymmetric' responses have been observed in concentrated industries (Lieberman, 1987a). On the other hand, firms in a production holdback environment, no matter whether they are incumbents or new entrants, should recognize that investment is likely to take place by all parties and hence they need to structure their decisions to avoid industry excess capacity. This type of 'symmetric' response has been observed in the brick industry (Wood, 2005). For a potential entrant, entering an industry with production holdback possibilities and long lead times gives a greater chance of success, rather than entering an industry with clearance and short lead times. Overall, an entrant should act with aggressive capacity investment under holdback production, but act passively under clearance production.

A central message of this paper is the importance of the link between a firm's operations (production policy) and its competitive environment (industry structure, production technology, and its costs of investment and production). This paper makes contributions to theory of operations strategy, in particular for capacity strategy. First we characterize the equilibrium solution of the strategic capacity game in a way that is similar to the well-known $(s, S)$ policy from inventory and supply chain theory (Scarf, 1960). But in addition, we see this paper as advancing the theoretical foundation of capacity strategy by analyzing competitive outcome under different operational characteristics. 


\section{References}

Anand, K.S., Girotra, K., 2007. The strategic perils of delayed differentiation. Management Science $53(5), 697-712$.

Anupindi, R., Jiang, L., 2008. Capacity investment under postponement strategies, market competition, and demand uncertainty. Management Science 54 (11), 1876-1890.

Asano, H., 2002. An empirical analysis of lumpy investment: The case of US petroleum refining industry. Energy Economics 24 (6) 629-645.

Cachon, G., Netessine, S., 2004. Game theory in supply chain analysis. In Simchi-Levi, D., Wu, S.D., Shen (Eds), Z.J. M., Handbook of Quantitative Supply Chain Analysis: Modeling in the E-Business Era. Boston, MA: Kluwer Academic Publishers.

Chen, M.-J., MacMillan, I.C., 1992. Nonresponse and delayed response to competitive Moves: The roles of competitor dependence and action irreversibility. Academy of Management Journal 35 (3), 359-370.

Chen, M.-J., Venkataraman, S., Black, S.S., MacMillan, I.C., 2002. The role of irreversibilities in competitive interaction: Behavioral considerations from organizational theory. Managerial and Decision Economics 23 (4-5), 187-207.

Chevalier-Roignant, B., Flath, C.M., Trigeorgis, L., 2011. Strategic investment under uncertainty: A synthesis. European Journal of Operational Research 215 (3), 639-650.

Christensen, C., 1997. The Innovator's Dilemma. Boston, MA: Harvard Business School Press.

Chronopoulos, M., Reyck, B.D., Siddiqui, A., 2011. Optimal investment under operational flexibility, risk aversion, and uncertainty. European Journal of Operational Research 213 (1), 221-237.

Dearden, J.A., Lilien, G.L., Yoon, E., 1999. Marketing and production capacity strategy for nondifferentiated products: Winning and losing at the capacity cycle game. International Journal of Research in Marketing, 16 (1), 57-74.

Dixit, A., 1980. The role of investment in entry-deterrence. Economic Journal 90 (357), 95-106.

Eaton, B.C., Ware, R., 1987. A theory of market structure with sequential entry. Rand Journal of Economics 16 (1), 1-16.

Ghemawat, P. 1984. Capacity expansion in the titanium dioxide industry. Journal of Industrial Economics 33 (2) 145-63.

Ghemawat, P., Cassiman, B. 2007. Introduction to the special issue on strategic dynamics. Management Science 53(4) 529-536.

Goyal, M., Netessine, S., 2007. Strategic technology choice and capacity investment under demand uncertainty. Management Science 53 (2), 192-207.

Hayes, R., Pisano, G., Upton, D., Wheelwright, S., 2005. Operations, Strategy, and Technology: Pursuing the Competitive Edge. John Wiley \& Sons, Inc.

Hendricks, K.B., Singhal, V.R, Wiedman, C.I., 1995. The impact of capacity expansion on the market value of the firm. Journal of Operations Management 12 (3-4), 259-272.

Koeva, P., 2000. The facts about time-to-build. Working Paper no. WP/00/138, International Monetary Fund. 
Kreps, D.M., Scheinkman, J.A., 1983. Quantity precommitment and Bertrand competition yield Cournot outcomes. Bell Journal of Economics 14 (2), 326-337.

Krishnan, M., Röller, L.-H., 1993. Preemptive investment with resalable capacity. Rand Journal of Economics 24 (4), 479-502.

Lieberman, M.B., 1987a. Postentry investment and market structure in the chemical processing industries. RAND Journal of Economics 18 (4), 533-549.

Lieberman, M.B., 1987b. Strategies for capacity expansion. Sloan Management Review 28 (4), 19-27.

Lieberman, M.B., 1987c. Excess capacity as a barrier to entry: An Empirical Appraisal. Journal of Industrial Economics 35 (4), 607-627.

Mahajan, S., van Ryzin, G., 2001. Inventory competition under dynamic consumer choice. Operations Research 49 (5), 464-657.

Porter, M., 1980. Competitive Strategy. New York: Free Press.

Rhim, H., Ho, T.H., Karmarkar, U.S., 2003. Competitive location, production, and market selection. European Journal of Operational Research 149 (1), 211-228.

Scarf, H. 1960. The optimality of $(s, S)$ policies in the dynamic inventory problem. In Arrow, K.J., Karlin, S., Suppes, P. (Eds.), Mathematical Methods in the Social Science. Stanford, CA: Stanford University Press.

Schelling, T., 1960. The Strategy of Conflict. Boston, MA: Harvard Business School Press.

Shapiro, C., 1986. Exchange of cost information in oligopoly. Review of Economic Studies 53 (3), 433-446.

Singh, N., Vives, X., 1984. Price and quantity competition in a differentiated duopoly. RAND Journal of Economics 15 (4), 546-554.

Spulber, D.F., 1981. Capacity, output, and sequential entry. American Economic Review 71(June), 503-514.

Swinney, R., Cachon, G., Netessine, S., 2011. Capacity Investment Timing by Start-ups and Established Firms in New Markets. Management Science 57 (4), 763-777.

Tirole, J., 1988. The Theory of Industrial Organization. Cambridge, Massachusetts, London: The MIT Press.

Van Mieghem, J.A., Dada, M., 1999. Price versus production postponement: Capacity and competition. Management Science 45 (12), 1631-1649.

Van Mieghem, J.A., 2003. Capacity management, investment and hedging: Review and recent development. Manufacturing \& Service Operations Management 5 (4), 269-302.

Ware, R., 1984. Sunk costs and strategic commitment: A proposed three-stage equilibrium. Economic Journal 94 (374), 370-378.

Wood, A., 2005. Investment interdependence and the coordination of lumpy investments: Evidence from the British brick industry. Applied Economics 37 (1), 37-49.

Wu, S.D., Erkoc, E., Karabuk, S., 2005. Managing capacity in the high-tech industry: A review of literature. Engineering Economist 50 (2), 125-158.

Ye, Q., Duenyas, I., 2007. Optimal capacity investment decisions with two-sided fixed capacity adjustment costs. Operations Research 55 (2), 272-283. 


\section{Supplementary Material for “Competition through capacity investment under asymmetric existing capacities and costs"}

Before giving the proof of Theorem 1 it is helpful to establish a result that gives the general form of the solution involving an expansion point and expansion level.

Lemma 5. Suppose that $\pi_{i}$ is concave in its first argument and let

$$
g_{i}\left(x_{i}, x_{j}\right) \equiv \pi_{i}\left(x_{i}, x_{j}\right)-W_{i} x_{i}
$$

Then there are real valued functions, $\bar{s}_{i}\left(x_{j}\right)$ and $\bar{S}_{i}\left(x_{j}\right)$, where, for each $x_{j}, \bar{S}_{i}\left(x_{j}\right)$ is the choice of $x_{i} \in\left(z_{i}, \infty\right)$ which maximizes $g_{i}\left(x_{i}, x_{j}\right)$ over this range, and $\bar{s}_{i}\left(x_{j}\right)$ is the smallest value of $\lambda$ for which $g_{i}\left(\lambda, x_{j}\right)=g_{i}\left(\bar{S}_{i}\left(x_{j}\right), x_{j}\right)-K_{i}$. Given the existing capacity pair $\left(z_{i}, z_{j}\right)$ and conjecturing the rival's capacity choice of $x_{j}$, an optimal capacity level for firm $i$ is

$$
\bar{x}_{i}= \begin{cases}\bar{S}_{i}\left(x_{j}\right) & \text { if } z_{i} \leq \bar{s}_{i}\left(x_{j}\right) \\ z_{i} & \text { otherwise. }\end{cases}
$$

Proof. We can rewrite $\Pi_{i}$ as

$$
\Pi_{i}\left(z_{i}, x_{j}\right)=W_{i} z_{i}+\max \left(g_{i}\left(z_{i}, x_{j}\right), \max _{x_{i}>z_{i}}\left[g_{i}\left(x_{i}, x_{j}\right)-K_{i}\right]\right) .
$$

If the function $\pi_{i}$ is strictly concave in its first argument, then so is the function $g_{i}$. We can easily check that $\pi_{i}\left(x_{i}, x_{j}\right)$ is bounded and so there is a unique maximizer of $g_{i}\left(x_{i}, x_{j}\right)$ over the range $\left(z_{i}, \infty\right)$. Thus the equation for $\Pi_{i}$ is equivalent to

$$
\Pi_{i}\left(z_{i}, x_{j}\right)= \begin{cases}W_{i} z_{i}+g_{i}\left(\bar{S}_{i}\left(x_{j}\right), x_{j}\right)-K_{i} & \text { for } z_{i} \leq \bar{s}_{i}\left(x_{j}\right), \\ W_{i} z_{i}+g_{i}\left(z_{i}, x_{j}\right) & \text { otherwise }\end{cases}
$$

with the functions $\bar{s}_{i}(\cdot)$ and $\bar{S}_{i}(\cdot)$ defined in the lemma statement. If $z_{i} \leq \bar{s}_{i}\left(x_{j}\right)$, then $g_{i}\left(z_{i}, x_{j}\right) \leq$ $g_{i}\left(\bar{S}_{i}\left(x_{j}\right), x_{j}\right)-K_{i}$ and, therefore, it is optimal to invest in bringing the capacity level up to $\bar{S}_{i}\left(x_{j}\right)$. If $\bar{s}_{i}\left(x_{j}\right)<z_{i} \leq \bar{S}_{i}\left(x_{j}\right)$, then, by the strict concavity of $g_{i}, g_{i}\left(z_{i}, x_{j}\right)>g_{i}\left(\bar{S}_{i}\left(x_{j}\right), x_{j}\right)-K_{i}$, so it is optimal not to invest. If $z_{i}>\bar{S}_{i}\left(x_{j}\right)$, it is also optimal not to invest due to the strict concavity of $g_{i}$. Note that $\bar{s}_{i}\left(x_{j}\right)<\bar{S}_{i}\left(x_{j}\right)$ since $K_{i}>0$, and the derivative of $g_{i}$ at $\bar{s}_{i}$ is positive.

Now we prove Theorem 1 by considering a number of cases which deal with different regions for $z_{i}$ and $x_{j}$. It will be helpful to split the $\Phi_{0}$ region in $\left(x_{i}, x_{j}\right)$ space into three:

$$
\begin{aligned}
& \Phi_{1} \equiv\left\{\left(x_{i}, x_{j}\right) \mid 0 \leq x_{i}<y_{i}^{c} \text { and } 0 \leq x_{j}<y_{j}^{c}\right\}, \\
& \Phi_{2} \equiv\left\{\left(x_{i}, x_{j}\right) \mid 0 \leq x_{i}<y_{i}^{c} \text { and } y_{j}^{c} \leq x_{j}<y_{j}^{a}\left(x_{i}\right)\right\}, \\
& \Phi_{3} \equiv\left\{\left(x_{i}, x_{j}\right) \mid y_{i}^{c} \leq x_{i}<y_{i}^{a}\left(x_{j}\right) \text { and } 0 \leq x_{j}<y_{j}^{c}\right\},
\end{aligned}
$$




\section{Proof of Theorem 1:}

Case 1. $\left(z_{i}, x_{j}\right) \in \Phi_{5} \cup \Phi_{6}$

In this case we have $z_{i} \geq \min \left(y_{i}^{c}, y_{i}^{a}\left(x_{j}\right)\right)$ so after investment the same inequality holds and $\left(x_{i}, x_{j}\right) \in \Phi_{5} \cup \Phi_{6}$. From Lemma 3(iii) and 3(iv) the equilibrium in the production game is independent of the value of $x_{i}$. Therefore, an investment by firm $i$ would involve cost without benefit and hence the best response of firm $i$ is not to invest.

Case 2. $\left(z_{i}, x_{j}\right) \in \Phi_{1} \cup \Phi_{3}$

In this case we have $z_{i}<y_{i}^{a}\left(x_{j}\right)$ and $x_{j} \leq y_{j}^{c}$. By Lemma 3 the upper bound of required capacity in the production game is $y_{i}^{a}\left(x_{j}\right)$ and so investment does not take place beyond that level, i.e. $z_{i} \leq x_{i} \leq y_{i}^{a}\left(x_{j}\right)$. In this case the best production quantity for each firm equals its capacity, using Lemma 3. Thus the operating profit function is

$$
\pi_{i}\left(x_{i}, x_{j}\right)=\left(A-x_{i}-x_{j}-V_{i}\right) x_{i},
$$

which is strictly concave in $x_{i}$ over the region of interest for each $x_{j}$. Hence we can apply Lemma 4 where the function $g_{i}$ is

$$
g_{i}\left(x_{i}, x_{j}\right)=\left(A-x_{i}-x_{j}-V_{i}\right) x_{i}-W_{i} x_{i},
$$

which is concave for every $x_{j}$. The maximum is achieved when $x_{i}$ is at the expansion level function of firm $i$, and so taking derivatives we obtain

$$
S_{i}^{L}\left(x_{j}\right)=\frac{A-V_{i}-x_{j}-W_{i}}{2}=y_{i}^{a}\left(x_{j}\right)-\frac{W_{i}}{2} .
$$

The expansion point function of firm $i$ is

$$
s_{i}^{L}\left(x_{j}\right)=\min \left\{\lambda \mid g_{i}\left(\lambda, x_{j}\right)=g_{i}\left(S_{i}^{L}\left(x_{j}\right), x_{j}\right)-K_{i}\right\} .
$$

So $s_{i}^{L}\left(x_{j}\right)$ is the smaller root of the quadratic

$$
\left(A-\lambda-x_{j}-V_{i}\right) \lambda-W_{i} \lambda=\left(\frac{A-V_{i}-x_{j}-W_{i}}{2}\right)^{2}-K_{i}
$$

and hence

$$
s_{i}^{L}\left(x_{j}\right)=\frac{A-V_{i}-x_{j}-W_{i}}{2}-\sqrt{K_{i}} .
$$

Hence from Lemma 4 , if $0 \leq z_{i} \leq s_{i}^{L}\left(x_{j}\right)$ then $x_{i}=S_{i}^{L}\left(x_{j}\right)$ and otherwise, $x_{i}=z_{i}$.

Case 3. $\left(z_{i}, x_{j}\right) \in \Phi_{4}$

In this case, $z_{i}<y_{i}^{c}$ and $x_{j} \geq y_{j}^{a}\left(z_{i}\right)$. Thus $x_{j}>y_{j}^{c}$ and from Lemmas 3(ii) and 3(iv), we know that if $x_{i} \geq y_{i}^{c}$ after firm $i$ 's investment decision, then the equilibrium output $\left(y_{i}^{c}, y_{j}^{c}\right)$ occurs in the production game; otherwise, the equilibrium output $\left(x_{i}, y_{j}^{a}\left(x_{i}\right)\right)$ occurs in the production game. Therefore, firm $i$ 's capacity choice is in the range $\left[z_{i}, y_{i}^{c}\right]$ since firm $i$ never produces more than $y_{i}^{c}$ in the production game. 
The operating profit function for firm $i$ is

$$
\pi_{i}\left(x_{i}, y_{j}^{a}\left(x_{i}\right)\right)=\left(A-x_{i}-y_{j}^{a}\left(x_{i}\right)-V_{i}\right) x_{i}
$$

which is strictly concave in $x_{i}$. Hence the approach of Lemma 5 can be used, with $g_{i}$ allowing for the response of firm $j$. Thus

$$
\begin{aligned}
g_{i}\left(x_{i}, y_{j}^{a}\left(x_{i}\right)\right) & =\pi_{i}\left(x_{i}, y_{j}^{a}\left(x_{i}\right)\right)-W_{i} x_{i} \\
& =\left(A-x_{i}-y_{j}^{a}\left(x_{i}\right)-V_{i}\right) x_{i}-W_{i} x_{i} .
\end{aligned}
$$

Maximizing over $x_{i}$ gives

$$
\frac{\partial g_{i}\left(x_{i}, y_{j}^{a}\left(x_{i}\right)\right)}{\partial x_{i}}=\frac{A}{2}-x_{i}-V_{i}+\frac{V_{j}}{2}-W_{i}=0
$$

and hence the maximum is at $x_{i}=3 y_{i}^{c} / 2-W_{i}$. But from Assumption 2, $y_{i}^{c} / 2>W_{i}$ and so this maximum occurs at a value greater than $y_{i}^{c}$. Hence we can deduce that the expansion level of firm $i$ is $y_{i}^{c}$. In other words if investment takes place it is best to invest up to a level $y_{i}^{c}$, when both firms will produce at the unconstrained Cournot equilibrium $\left(y_{i}^{c}, y_{j}^{c}\right)$.

The expansion point function is the lowest root of the equation

$$
\begin{aligned}
g_{i}\left(\lambda, y_{j}^{a}(\lambda)\right) & =\pi_{i}\left(y_{i}^{c}, y_{j}^{c}\right)-W_{i} y_{i}^{c}-K_{i} \\
& =\left(A-W_{i}-V_{i}-y_{i}^{c}-y_{j}^{c}\right) y_{i}^{c}-K_{i}
\end{aligned}
$$

This is a quadratic

$$
\left(A-\lambda-\frac{A-V_{j}-\lambda}{2}\right) \lambda-\left(V_{i}+W_{i}\right) \lambda=\frac{\left(A-2 V_{i}+V_{j}-3 W_{i}\right)\left(A-2 V_{i}+V_{j}\right)}{9}-K_{i}
$$

which has roots (after some algebra):

$$
\frac{\left(A+V_{j}-2 V_{i}\right)}{2}-W_{i} \pm \sqrt{2 K_{i}+\left(\frac{A-2 V_{i}+V_{j}}{6}-W_{i}\right)^{2}} .
$$

The smaller root is $s_{i}^{B}$. From Lemma 4, we know that: if $0 \leq z_{i} \leq s_{i}^{B}$ then $x_{i}=y_{i}^{c}$; otherwise, $x_{i}=z_{i}$.

Case 4. $\left(z_{i}, x_{j}\right) \in \Phi_{2}$

In this case, $z_{i}<y_{i}^{c}$ and $y_{j}^{c}<x_{j}<y_{j}^{a}\left(z_{i}\right)$. The analysis of optimal behavior in this region is complex. If firm $i$ has decided to invest in additional capacity, there are two possible equilibrium outcomes in the production game: either (1) the production equilibrium is $\left(x_{i}, x_{j}\right)$ if $\left(x_{i}, x_{j}\right) \in \Phi_{2}$, or (2) the production equilibrium is $\left(x_{i}, y_{j}^{a}\left(x_{i}\right)\right)$ if $\left(x_{i}, x_{j}\right) \in \Phi_{4}$. In fact, the function $\pi_{i}$ is not unimodal as a result of the equilibrium output in the production game being different between regions $\Phi_{2}$ and $\Phi_{4}$.

We begin by considering firm $i$ 's best response function under Assumption 2 for $\left(x_{i}, x_{j}\right) \in \Phi_{2}$. Given $x_{j}$, the upper boundary of $\Phi_{2}$ is reached when $x_{i}$ takes the value

$$
x_{i}=\left(y_{j}^{a}\right)^{-1}\left(x_{j}\right)=A-V_{j}-2 x_{j} .
$$


While $\left(x_{i}, x_{j}\right) \in \Phi_{2}$, i.e. $x_{i}$ is in the range $\left(z_{i}, A-V_{j}-2 x_{j}\right)$, the operating profit function $\pi_{i}\left(x_{i}, x_{j}\right)$ follows the quadratic function (A1) given above. However, if $\left(x_{i}, x_{j}\right) \in \Phi_{4}$ after firm $i$ invests, then $y_{j}$ is reduced to $y_{j}^{a}\left(x_{i}\right)$ in the production phase of the game (see Lemma 3(ii)). This leads the operating profit function of firm $i$ to be a different quadratic function, (A2).

First observe that if firm $i$ invests enough, so that $\left(x_{i}, x_{j}\right) \in \Phi_{4}$, then under Assumption 2, the net profit $\pi_{i}\left(x_{i}, y_{j}^{a}\left(x_{i}\right)\right)-W_{i}\left(x_{i}-z_{i}\right)-K_{i}$ is still increasing at $x_{i}=y_{i}^{c}$ (as in Case 3 above). It is easy to see that investment to a level beyond $y_{i}^{c}$ is not worthwhile and so the profit is maximized at $x_{i}=y_{i}^{c}$. Hence the maximum value of firm $i$ 's profit if it invests to a level $x_{i}$ where $\left(x_{i}, x_{j}\right) \in \Phi_{4}$ is

$$
\pi_{i}\left(y_{i}^{c}, y_{j}^{c}\right)-W_{i}\left(y_{i}^{c}-z_{i}\right)-K_{i}=W_{i} z_{i}+g_{i}\left(y_{i}^{c}, y_{j}^{c}\right)-K_{i} .
$$

We also need to consider the case where firm $i$ 's investment decision leaves $\left(x_{i}, x_{j}\right) \in \Phi_{2}$. In this case, we know from Lemma $3(\mathrm{i})$ that $y_{i}=x_{i}$ for each $i$ and so the best choice of $x_{i}$ is given by $S_{i}^{L}\left(x_{j}\right)$ and the maximum value of profit for firm $i$ if its investment decision makes $\left(x_{i}, x_{j}\right) \in \Phi_{2}$ is

$$
W_{i} z_{i}+g_{i}\left(S_{i}^{L}\left(x_{j}\right), x_{j}\right)-K_{i}
$$

which needs to be compared to (A3) above. Later we will establish that in the cases where (A4) is better than (A3) then $x_{i}=S_{i}^{L}\left(x_{j}\right)$ will satisfy the constraint that $\left(x_{i}, x_{j}\right) \in \Phi_{2}$.

Let

$$
\begin{aligned}
\Psi_{i}\left(x_{j}\right) & \equiv g_{i}\left(y_{i}^{c}, y_{j}^{c}\right)-g_{i}\left(S_{i}^{L}\left(x_{j}\right), x_{j}\right) \\
& =\frac{\left(2 y_{j}^{c}-2 x_{j}-W_{i}\right) W_{i}-2\left(y_{j}^{c}-x_{j}\right)\left(y_{i}^{c}+y_{i}^{a}\left(x_{j}\right)\right)}{4}
\end{aligned}
$$

be the difference between (A3) and (A4). Note that $\Psi_{i}$ is a concave quadratic because the coefficient of $x_{j}^{2}$ is negative. Thus $\Psi_{i}\left(x_{j}\right)$ is negative below the lower root of the quadratic

$$
\left(2 y_{j}^{c}-2 x_{j}-W_{i}\right) W_{i}-\left(y_{j}^{c}-x_{j}\right)\left(2 y_{i}^{c}+A-V_{i}-x_{j}\right)=0,
$$

i.e. for $x_{j}$ values less than

$$
\vartheta_{i} \equiv A-V_{i}-W_{i}-2 \sqrt{y_{i}^{c}\left(y_{i}^{c}-W_{i}\right)} .
$$

(From Assumption 2 this is well-defined). For these $x_{j}$ values (A4) is larger than (A3) and the expansion level for firm $i$ is $S_{i}^{L}\left(x_{j}\right)$. Note that $\vartheta_{i}>y_{j}^{c}$ since

$$
\begin{aligned}
\vartheta_{i}-y_{j}^{c} & =A-V_{i}-W_{i}-\frac{A-2 V_{j}+V_{i}}{3}-2 \sqrt{y_{i}^{c}\left(y_{i}^{c}-W_{i}\right)} \\
& =2 y_{i}^{c}-W_{i}-2 \sqrt{y_{i}^{c}\left(y_{i}^{c}-W_{i}\right)} \\
& =\left(\sqrt{y_{i}^{c}}-\sqrt{\left(y_{i}^{c}-W_{i}\right)}\right)^{2}>0 .
\end{aligned}
$$

We want to show that, when $x_{j}$ is less than $\vartheta_{i}$, the expansion level suggested, which is $S_{i}^{L}\left(x_{j}\right)$, is still in $\Phi_{2}$. To do this, we introduce $\xi_{i}$ for the intersection of $S_{i}^{L}\left(x_{j}\right)$ and the upper boundary $x_{j}=y_{j}^{a}\left(x_{i}\right)$ of region $\Phi_{2}$, which occurs at an $x_{j}$ value of

$$
\xi_{i} \equiv y_{j}^{a}\left(x_{i}\right)=y_{j}^{c}+\frac{W_{i}}{3}
$$


by solving $y_{j}^{a}\left(S_{i}^{L}(\xi)\right)=\xi$ (note that, under Assumption 2, $\xi_{i}<y_{j}^{a}(0)$ which is the highest value in $\left.\Phi_{2}\right)$. Now

$$
\xi_{i}-\vartheta_{i}=2\left[\frac{2 W_{i}}{3}-y_{i}^{c}+\sqrt{y_{i}^{c}\left(y_{i}^{c}-W_{i}\right)}\right] .
$$

But using Assumption 2, $y_{i}^{c}>2 W_{i}$ and so

$$
y_{i}^{c}\left(y_{i}^{c}-W_{i}\right)-\left(y_{i}^{c}-\frac{2 W_{i}}{3}\right)^{2}=\frac{W_{i}}{3}\left(y_{i}^{c}-\frac{4 W_{i}}{3}\right)>0 .
$$

Thus

$$
\sqrt{y_{i}^{c}\left(y_{i}^{c}-W_{i}\right)}>y_{i}^{c}-\frac{2 W_{i}}{3},
$$

and $\xi_{i}>\vartheta_{i}$ as we require is obtained.

This completes the analysis of the expansion level function for this case and we now consider the expansion point function giving the condition for investment for $\left(z_{i}, x_{j}\right) \in \Phi_{2}$. For $y_{j}^{c} \leq x_{j}<\vartheta_{i}$ the analysis is essentially the same as in Case 2 and we can show that the expansion point function of firm $i$ is $s_{i}^{L}\left(x_{j}\right)$.

For $\vartheta_{i} \leq x_{j}<y_{j}^{a}(0)$, we start by defining a function

$$
\begin{aligned}
G_{i}\left(\lambda, x_{j}\right) & \equiv \pi_{i}\left(y_{i}^{c}, y_{j}^{c}\right)-W_{i}\left(y_{i}^{c}-\lambda\right)-K_{i}-\pi_{i}\left(\lambda, x_{j}\right) \\
& =\lambda\left[\lambda-2 y_{i}^{a}\left(x_{j}\right)+W_{i}\right]+y_{i}^{c}\left(y_{i}^{c}-W_{i}\right)-K_{i},
\end{aligned}
$$

which is the net gain from investing up to level $y_{i}^{c}$, given capacity $\lambda\left(\in\left[0,\left(y_{j}^{a}\right)^{-1}\left(x_{j}\right)\right]\right)$ and the other player's capacity $x_{j}\left(>y_{j}^{c}\right)$. The function $G_{i}$ is convex and quadratic in its first argument. Investment is worthwhile if $G_{i}$ is positive and the expansion point function is simply the lower root of the equation $G_{i}\left(\lambda, x_{j}\right)=0$, which is:

$$
\phi_{i}\left(x_{j}\right)=y_{i}^{a}\left(x_{j}\right)-\frac{W_{i}}{2}-\sqrt{\varepsilon_{i}\left(x_{j}\right)}
$$

where

$$
\varepsilon_{i}\left(x_{j}\right) \equiv\left(y_{i}^{a}\left(x_{j}\right)-\frac{W_{i}}{2}\right)^{2}-y_{i}^{c}\left(y_{i}^{c}-W_{i}\right)+K_{i} .
$$

We can also check that there is no problem caused by the fact that, in this case, if the firm does not invest the payoff is not monotonic in capacity - which could suggest that there will be more complex behavior involving going back to investing for higher values of $x_{i}$. To show that this does not happen, we want to show that if

$$
\phi_{i}\left(x_{j}\right)<\left(y_{j}^{a}\right)^{-1}\left(x_{j}\right),
$$

then $G_{i}\left(\lambda, x_{j}\right)$ is still negative at the boundary $\lambda=\left(y_{j}^{a}\right)^{-1}\left(x_{j}\right)=A-V_{j}-2 x_{j}$. The condition (A5) is

$$
\frac{A-V_{i}-W_{i}-x_{j}}{2}-\sqrt{\varepsilon_{i}\left(x_{j}\right)}<A-V_{j}-2 x_{j} .
$$

Rearranging and squaring this becomes

$$
\left(\frac{A-V_{i}-W_{i}-x_{j}}{2}\right)^{2}-y_{i}^{c}\left(y_{i}^{c}-W_{i}\right)+K_{i}>\left(\frac{2 V_{j}-A-V_{i}-W_{i}+3 x_{j}}{2}\right)^{2} .
$$

Hence

$$
K_{i}-y_{i}^{c}\left(y_{i}^{c}-W_{i}\right)-\left(V_{j}-A+2 x_{j}\right)\left(V_{j}-V_{i}-W_{i}+x_{j}\right)>0 .
$$


But the left hand side of this inequality is simply $G_{i}\left(A-V_{j}-2 x_{j}, x_{j}\right)$ establishing the inequality we require. This completes the proof of Theorem 1.

We want to show that the expansion function is continuous. To do this we will modify the argument above to show that the function $\phi_{i}\left(x_{j}\right)$ crosses the boundary of $\Phi_{2}$ at $s_{i}^{B}$. Since $\phi_{i}\left(x_{j}\right)=\left(y_{j}^{a}\right)^{-1}\left(x_{j}\right)$ implies

$$
K_{i}-y_{i}^{c}\left(y_{i}^{c}-W_{i}\right)-\left(V_{j}-A+2 x_{j}\right)\left(V_{j}-V_{i}-W_{i}+x_{j}\right)=0 .
$$

This is a quadratic in $x_{j}$ and (after some algebra) we find that the roots are

$$
\frac{A-3 V_{j}+2 V_{i}}{4}+\frac{W_{i}}{2} \pm \frac{1}{2} \sqrt{2 K_{i}+\left(W_{i}-\frac{y_{i}^{c}}{2}\right)^{2}}
$$

and the upper root is exactly $y_{j}^{a}\left(s_{i}^{B}\right)$ (note that the lower root turns out to be less than $y_{j}^{c}$, and so is not relevant). We can also show that $\phi_{i}\left(\vartheta_{i}\right)=s_{i}^{L}\left(\vartheta_{i}\right)=\sqrt{y_{i}^{c}\left(y_{i}^{c}-W_{i}\right)}-\sqrt{K_{i}}$. Thus we have demonstrated the continuity of the expansion point function. We could also establish this result indirectly by observing that the cost of investing is a continuous function of the amount invested (away from 0 ) and the profit after investment is a continuous function of the final position. Therefore the maximum profit if it is decided to invest (optimizing over the amount) is continuous. The intersection of the two surfaces (profit from investing and profit from not investing) defines the expansion point function which must therefore be continuous.

Proof of Remark 2. We can also investigate the effect of moving a cost $\Delta$ from $V_{i}$ to $W_{i}$ on firm $i$ 's profit. Assume that $z_{j}=0$, i.e. firm $j$ is a new entrant. We will also suppose that a change which adds cost to the investment component $W_{i}$ includes an additional cost in respect of the existing capacity $z_{i}$. Suppose that $z_{i}<b_{i}$ and $0<b_{j}$ (e.g. $\left(z_{i}, 0\right)$ in region $\left.\Lambda_{1}\right)$ so that both firms invest and $\left(x_{i}, x_{j}\right)=\left(x_{i}^{C}, x_{j}^{C}\right)$. The profit to firm $i$ in this case is

$$
\Pi_{i}=\left(A-x_{i}^{C}-x_{j}^{C}\right) x_{i}^{C}-V_{i} x_{i}^{C}-W_{i} x_{i}^{C}-K_{i}
$$

(note that we have included the prior expenditure of $W_{i} z_{i}$ in this expression). Since $x_{i}^{C}, x_{j}^{C}$ and $V_{i}+W_{i}$ are all unchanged by the move of cost, there is no change in profit overall: there is a change in the timing of expenditure, rather than the amount of expenditure.

Next consider the case where $0<s_{j}\left(z_{i}\right)$ and $c_{i} \leq z_{i}<\vartheta_{j}$ (e.g. $\left(z_{i}, 0\right)$ in region $\left.\Lambda_{6}\right)$ so that firm $i$ does not invest and $x_{j}=S_{j}^{L}\left(z_{i}\right)$ which is unchanged by the move of costs. Moreover, in this region the production quantity for firm $i$ is equal to the capacity $z_{i}$ (see proof of Theorem 1, Case 4). Again there is no change in firm $i$ 's overall profit.

Now consider the case that $0<s_{j}\left(z_{i}\right)$ and $z_{i} \geq \vartheta_{j}$ (i.e. $\left(z_{i}, 0\right)$ in region $\Lambda_{8}$ ). Then firm $i$ does not invest and $x_{j}=y_{j}^{c}$. Now

$$
\Pi_{i}=\left(A-y_{i}^{c}-y_{j}^{c}\right) y_{i}^{c}-V_{i} y_{i}^{c}-W_{i} z_{i}-K_{i} .
$$


As $y_{i}^{c}$ increases by $2 \Delta / 3$ and $y_{j}^{c}$ decreases by $\Delta / 3$, we obtain

$$
\begin{aligned}
\Pi_{i}^{\text {new }}-\Pi_{i}= & \left(A-y_{i}^{c}-y_{j}^{c}-\frac{\Delta}{3}\right)\left(y_{i}^{c}+\frac{2 \Delta}{3}\right)-\left(V_{i}-\Delta\right)\left(y_{i}^{c}+\frac{2 \Delta}{3}\right) \\
& -\left(A-y_{i}^{c}-y_{j}^{c}\right) y_{i}^{c}+V_{i} y_{i}^{c}-\Delta z_{i} \\
= & \Delta\left(\frac{4}{3} y_{i}^{c}+\frac{4}{9} \Delta-z_{i}\right) .
\end{aligned}
$$

Thus, there will be an improvement in profit offset by a term $\Delta z_{i}$ which arises from the fact that not all the capacity built is used (in this region firm $i$ has an excess capacity endowment). Provided this excess capacity is not too great, then overall profits will improve.

The reduction in size of the region $\Lambda_{6} \cup \Lambda_{8}$ is mainly associated with changing particular scenarios from $\Lambda_{8}$ to $\Lambda_{10}$. If $\left(z_{i}, 0\right)$ is moved to $\Lambda_{10}$ as a result of moving a cost $\Delta$ from $V_{i}$ to $W_{i}$, then at the production stage firm $i$ moves from an environment with a competitor present to one without a competitor. Moreover production costs are decreased. Without doing the detailed calculations it is easy to see that there is an improvement in profit for firm $i$, again offset by a term $\Delta z_{i}$ related to the extra costs of capacity that is not used.

There may also be a change in profit if $\left(z_{i}, 0\right)$ is at a point which moves from $\Lambda_{8}$ to $\Lambda_{6}$ as the boundary changes. Then

$$
\begin{aligned}
\Pi_{i}^{\text {new }}-\Pi_{i} & =\left(A-z_{i}-S_{j}^{L}\left(z_{i}\right)\right) z_{i}-\left(V_{i}-\Delta\right) z_{i}-\left(A-y_{i}^{c}-y_{j}^{c}\right) y_{i}^{c}+V_{i} y_{i}^{c}-\Delta z_{i} \\
& =\frac{1}{2} z_{i}\left(3 y_{i}^{c}+W_{j}-z_{i}\right)-\left(y_{i}^{c}\right)^{2}
\end{aligned}
$$

Observe that this expression is positive when $z_{i}=y_{i}^{c}$ but becomes negative for $z_{i}$ large enough. This completes the proof.

Proof of Remark 4. We want to compare the overall profits arising from holdback and clearance. The two different environments may produce very similar results. From a comparison of Theorems 2 and 3, we can see that for cases (i) and (ii) of Theorem 2 the results with clearance are qualitatively similar to those with holdback. Differences arise when one or both firms have an excess capacity endowment at the start of the capacity game. To make the discussion more concrete suppose that firm $i$ is an entrant with $z_{i}=0$ and firm $j$ is an incumbent with $z_{j}>\vartheta_{i}$. Moreover for simplicity we will assume that there are no fixed costs so $K_{i}=K_{j}=0$. For holdback production, provided $s_{i}\left(z_{j}\right)>0$, we are in case (iii) and firm $i$ invests up to $y_{i}^{c}$ and the incumbent firm does not invest (note that when $K_{i}=0$, we have $s_{i}^{B}=y_{i}^{c}$ and so the condition $s_{i}\left(z_{j}\right)>0$ will usually hold). In the production game firm $i$ produces $y_{i}^{c}$ and firm $j$ produces $y_{j}^{c}$. This gives a profit to the entering firm $i$ of

$$
\left(A-y_{i}^{c}-y_{j}^{c}-V_{i}-W_{i}\right) y_{i}^{c}=\left(y_{i}^{c}-W_{i}\right) y_{i}^{c}
$$

The profit to the incumbent firm $j$ is

$$
\left(A-y_{i}^{c}-y_{j}^{c}-V_{j}\right) y_{j}^{c}=\left(y_{j}^{c}\right)^{2} .
$$


Now consider clearance production. There are two cases. If $s_{i}^{L}\left(z_{j}\right)>0$ then the entering firm invests an amount $S_{i}^{L}\left(z_{j}\right)$ otherwise firm $i$ does not enter. The condition for entering can be written as $z_{j}<A-V_{i}-W_{i}$. In this case the entering firm gets a profit of

$$
\left(A-S_{i}^{L}\left(z_{j}\right)-z_{j}-V_{i}-W_{i}\right) S_{i}^{L}\left(z_{j}\right)=\left(\frac{A-V_{i}-W_{i}-z_{j}}{2}\right)^{2}
$$

Since $z_{j}>\vartheta_{i}$ the profit made is less than $\left(y_{i}^{c}-W_{i}\right) y_{i}^{c}$; in other words, with clearance the entering firm makes less profit than with holdback. This is true also when the firm does not enter (making zero profit under clearance).

Now consider the incumbent firm: since $S_{i}^{L}\left(z_{j}\right)<y_{i}^{c}$ in this region, firm $i$ always produces less than under holdback. Hence the profit to firm $j$ were it to produce $y_{j}^{c}$ is greater than the profit (A6) under holdback production. Thus its profit from optimizing its production amount is also higher. This completes the proof.

Proof of Remarks 5 and 6. First, we assume that the firms employ clearance in production (we will use the notation $\left.\right|_{L}$ to indicate clearance). This game obviously degenerates into the standard Stackelberg duopoly with the equilibrium outcomes, $\left.x_{i}^{*}\right|_{L}=(A-W) / 2$ and $\left.x_{j}^{*}\right|_{L}=(A-W) / 4$, both of which are positive from Assumption 2. The equilibrium profits are

$$
\left.\pi_{i}^{*}\right|_{L}=(A-W)^{2} / 8 \text { and }\left.\pi_{j}^{*}\right|_{L}=(A-W)^{2} / 16 .
$$

And, we can see $\left.\pi_{i}^{*}\right|_{L}=\left.2 \pi_{j}^{*}\right|_{L}$.

For the sake of comparison, the firms are now assumed to employ holdback in production (we will use the notation $\left.\right|_{B}$ to indicate holdback). As before, Assumption 2 holds in the following analysis. Solving this problem backwards, we first consider firm $j$ 's decision given firm $i$ 's investment amount of $x_{i}$. Theorem 1 tells us that for $K=0$ such that $s(\cdot)=S(\cdot)$, firm $j$ 's best response of capacity investment over $x_{i}$ is

$$
\left.x_{j}^{*}\left(x_{i}\right)\right|_{B}=\left\{\begin{array}{cl}
S^{L}\left(x_{i}\right) & \text { for } x_{i} \leq \vartheta \\
y^{c} & \text { otherwise. }
\end{array}\right.
$$

Note that $S^{L}\left(x_{i}\right)>0$ because $S^{L}(\vartheta)>0$ (i.e. Assumption 2 rules out the trivial case where $S^{L}(x)<0$ for $x<\vartheta$ ). Substituting this into firm $i$ 's decision problem, we obtain firm $i$ 's profit function:

$$
\left.\max _{x_{i} \geq 0} \Pi_{i}\left(x_{i}\right)\right|_{B}= \begin{cases}P\left(x_{i}+S^{L}\left(x_{i}\right)\right) x_{i}-W x_{i}=\left(A-W-x_{i}\right) x_{i} / 2 & \text { for } x_{i} \leq \vartheta \\ P\left(2 y^{c}\right) y^{c}-W x_{i}=A^{2} / 9-W x_{i} & \text { otherwise. }\end{cases}
$$

Solving this, we obtain an equilibrium outcome:

$$
\begin{aligned}
& \left.x_{i}^{*}\right|_{B}=\vartheta=A-W-2 \sqrt{A(A-3 W)} / 3>y^{c}, \text { and } \\
& \left.x_{j}^{*}\right|_{B}=S^{L}(\vartheta)=(A-\vartheta-W) / 2=\sqrt{A(A-3 W)} / 3<y^{c},
\end{aligned}
$$

where $\left.x_{i}^{*}\right|_{B} \geq\left. x_{j}^{*}\right|_{B}$ since $\left.x_{i}^{*}\right|_{B}-\left.x_{j}^{*}\right|_{B}=A-W-\sqrt{A(A-3 W)} \geq 0$ since $(A-W)^{2}-[\sqrt{A(A-3 W)}]^{2}=$ $(A+W) W \geq 0$. The equilibrium profits are

$$
\left.\pi_{i}^{*}\right|_{B}=\frac{(A-W-\sqrt{4 A(A / 3-W) / 3}) \sqrt{4 A(A / 3-W) / 3}}{2} \text { and }\left.\pi_{j}^{*}\right|_{B}=\frac{A(A-3 W)}{9} \text {. }
$$


We can see $\left.\pi_{i}^{*}\right|_{B}>\left.\pi_{j}^{*}\right|_{B}>0$ from above.

In this sequential investment game, the leader has a first mover advantage and can predict that if its own capacity investment is at $\vartheta$ or more, the potential entrant will invest up to $y^{c}$ and then push all capacity into the market to force the leader to hold back some capacity. If this happens, the competition outcome is the standard Cournot duopoly and the leader would not gain any benefit by moving earlier. This is why the leader will choose to invest in capacity at a level $\vartheta$.

By the following facts:

$$
\left.x_{i}^{*}\right|_{L}>\left.x_{i}^{*}\right|_{B}>y^{c}>\left.x_{j}^{*}\right|_{B}>\left.x_{j}^{*}\right|_{L}
$$

and

$$
\left.\pi_{i}^{*}\right|_{L}>\left.\pi_{i}^{*}\right|_{B}>\left.\pi_{j}^{*}\right|_{B}>\left.\pi_{j}^{*}\right|_{L}>0
$$

we see that in the alternating decision scheme, holdback production weakens the commitment capability of preemptive capacity expansion (because $\left.x_{j}^{*}\right|_{B}>\left.x_{j}^{*}\right|_{L}$ and $\left.\pi_{j}^{*}\right|_{B}>\left.\pi_{j}^{*}\right|_{L}$ ) but the clearance strategies strengthens the commitment (because $\left.x_{i}^{*}\right|_{L}>\left.x_{i}^{*}\right|_{B}$ and $\left.\pi_{i}^{*}\right|_{L}>\left.\pi_{i}^{*}\right|_{B}$ ), as in the simultaneous decision scheme. Note that in the sequential setting with holdback, the leading firm invests more than the Cournot outcome of $y^{c}$ and the following firm invests less than $y^{c}$. Therefore, the first-mover advantage still exists in the sequential investment game with holdback. 